\title{
Reflections on a Science and Technology Agenda for 21st Century Disaster Risk Reduction
}

\section{Based on the Scientific Content of the 2016 UNISDR Science and Technology Conference on the Implementation of the Sendai Framework for Disaster Risk Reduction 2015-2030}

\author{
Amina Aitsi-Selmi ${ }^{1}$ - Virginia Murray ${ }^{1,2}$ - Chadia Wannous ${ }^{3} \cdot$ Chloe Dickinson $^{1} \cdot$ \\ David Johnston $^{4} \cdot$ Akiyuki Kawasaki $^{5} \cdot$ Anne-Sophie Stevance $^{6} \cdot$ Tiffany Yeung $^{7}$
}

Published online: 24 March 2016

(c) The Author(s) 2016. This article is published with open access at Springerlink.com

\begin{abstract}
The first international conference for the post2015 United Nations landmark agreements (Sendai Framework for Disaster Risk Reduction 2015-2030, Sustainable Development Goals, and Paris Agreement on Climate Change) was held in January 2016 to discuss the role of science and technology in implementing the Sendai Framework for Disaster Risk Reduction 2015-2030. The UNISDR Science and Technology Conference on the Implementation of the Sendai Framework for Disaster Risk Reduction 2015-2030 aimed to discuss and endorse plans that maximize science's contribution to reducing disaster risks and losses in the coming 15 years and bring together the diversity of stakeholders producing and using disaster
\end{abstract}

Virginia Murray

virginia.murray@phe.gov.uk

Amina Aitsi-Selmi

amina.aitsi-selmi@phe.gov.uk

1 Public Health England, London SE1 8UG, UK

2 Chair of the UNISDR Science and Technology Conference on the Implementation of the Sendai Framework for Disaster Risk Reduction 2015-2030, Vice-chair of the UNISDR Scientific and Technical Advisory Group (STAG), URL: https://www.unisdr.org/

3 United Nations Office for Disaster Risk Reduction, Geneva, Switzerland

4 Joint Centre for Disaster Research, GNS Science/Massey University, Wellington 6140, New Zealand

5 University of Tokyo, Tokyo 113-8654, Japan

6 International Council for Science, 75116 Paris, France

7 Hong Kong Jockey Club Disaster Preparedness and Response Institute Overseas Training Fellow, Hong Kong, China risk reduction (DRR) science and technology. This article describes the evolution of the role of science and technology in the policy process building up to the Sendai Framework adoption that resulted in an unprecedented emphasis on science in the text agreed on by 187 United Nations member states in March 2015 and endorsed by the United Nations General Assembly in June 2015. Contributions assembled by the Conference Organizing Committee and teams including the conference concept notes and the conference discussions that involved a broad range of scientists and decision makers are summarized in this article. The conference emphasized how partnerships and networks can advance multidisciplinary research and bring

With contributions from (for acronyms see list at the end of the article) Delilah Al Khudhairy (EC JRC), David Alexander (UCL Institute for Risk and Disaster Reduction), Blerta Aliko (UN Women), Claire Allen (Evidence Aid), Tee Wee Ang (UNESCO), Paul Arbon (Torrens Resilience Institute), Ali Ardalan (Harvard Humanitarian Initiative), Pedro Basabe (UNISDR), Dominique Berod (GEO; GEOSS), Sanjaya Bhatia (UNISDR), Danielle Bicknell (UNESCO), Kevin Blanchard (Public Health England), Geoffrey Boulton (University of Edinburgh), Julie Calkins (UKCDS), Tony Capon (UNU-IIGH)), Omar-Dario Cardona (Universidad Nacional de Colombia, Manizales; IRDR ICoE on Understanding Risk \& Safety), Anne Castleton (IRDR), Emily Ying Yang Chan (Collaborating Centre for Oxford University and the Chinese University of Hong Kong for Disaster and Medical Humanitarian Response), Gloria Kwong Wai Chan (Collaborating Centre for Oxford University and the Chinese University of Hong Kong for Disaster and Medical Humanitarian Response), Ian Clark (EC JRC), Andrew Collins (Department of Geography, Northumbria University), Christina Corbane (EC JRC), Sue Corbett (previously INASP; Saha Astitva), Lydia Cumiskey (Young Scientists Platform on DRR, UN MGCY), Tom De Groeve (EC JRC), Helene Jacot Des Combes (Pacific Forum), Emily Dickinson (ODI), Craig Duncan (UNISDR), Daniele Ehrlich (EC JRC), Lucy Fagan (Global Health Next Generation Network), Dafna Feinholz (UNESCO), Shirley 
together science, policy, and practice; how disaster risk is understood, and how risks are assessed and early warning systems are designed; what data, standards, and innovative practices would be needed to measure and report on risk reduction; what research and capacity gaps exist and how difficulties in creating and using science for effective DRR can be overcome. The Science and Technology Conference achieved two main outcomes: (1) initiating the UNISDR Science and Technology Partnership for the implementation of the Sendai Framework; and (2) generating discussion and agreement regarding the content and endorsement process of the UNISDR Science and Technology Road Map to 2030.

Keywords Disaster risk reduction - Sendai Framework implementation $\cdot$ Science and Technology

Conference $\cdot$ Science-policy interface

\section{Background: The Evolving Relationship Between Science and Disaster Risk Reduction}

The year 2015 was a historic year in global policy with the publication of three landmark UN agreements:

(1) The Sendai Framework for Disaster Risk Reduction 2015-2030 (Sendai Framework) that aims to reduce disaster losses in lives, livelihoods, and health, adopted in March 2015 in Sendai, Japan by 187 United Nations (UN) member states;

(2) The Sustainable Development Goals (SDGs)—successors of the Millennium Development Goalsagreed in September 2015 in New York, USA by 193 countries; and

(3) The Paris Agreement on Climate Change, agreed on in December 2015 at the Paris Climate Conference (CoP21) by 195 countries.

The rare coincidence of three such agreements is an opportunity of global significance for building coherence across these policy streams. Over the implementation period of these three agreements between 2015 and 2030, a real opportunity exists for improving people's health and preserving their environment. The Sendai Framework includes unprecedented emphasis on the role of science in understanding and delivering risk reduction and is the result of a unique opening in the policy space bringing political will, the imperative for change, and the availability of scientific input together (UNISDR 2016i).

A turning point in the history of disaster risk reduction (DRR) was the intergovernmental commitment through the United Nations to foster disaster risk management (DRM) during the International Decade for Natural Disaster Reduction (1990-1999). At the first World Conference on Natural Disaster Reduction in 1994 the Yokohama Strategy and Plan of Action for a Safer World: Guidelines for
Feldmann-Jensen (School of Criminology, Criminal Justice, and Emergency Management, California State University), Maureen Fordham (GDN), Ruth Francis (Springer), Joel Gill (Young Scientists Platform on DRR, UN MGCY), Louis Gritzo (FM Global), Aakriti Grover (Young Scientists Platform on DRR, UN MGCY), Donovan Guttieres (Young Scientists Platform on DRR, UN MGCY), Michael Hagenlocher (UNU-EHS), Alasdair Hainsworth (WMO), Haruo Hayashi (NIED), Moa M. Herrgård (Young Scientists Platform on DRR, UN MGCY), Ailsa Holloway (RADAR, Stellenbosch University, South Africa (PeriPeri U)), Alistair Humphrey (Canterbury District Health Board), Gavin Iley (UK Met Office), Lorenza Jachia (UNECE), Jeroen Jansen (Evidence Aid), Graham Jukes (Chartered Institute of Environmental Health), Aashish Khullar (Young Scientists Platform on DRR, UN MGCY), Leah Kimber (University of Geneva), Julian Kinderlerer (European Group on Ethics; UCT), Toshio Koike (University of Tokyo; ICHARM), Ajay Kumar (Young Scientists Platform on DRR, UN MGCY), Ian Lisk (UK Met Office), Jochen Luther (WMO), Alexandros Makarigakis (UNESCO), Aleksandrina Mavrodieva (WHS), Gordon McBean (ICSU), Junko Mochizuki (IIASA), Robert Muir-Wood (RMS), Genene Mulugeta (Baltic University; ICSU Regional Office Africa), Donal O’Mathúna (Dublin City University; Disaster Bioethics
IS1201 COST Action), Yuichi Ono (International Research Institute of Disaster Science, Tohoku University), Nora Papp (ICSU), William Patton (IRDR), Mark Pelling (King's College London; IRDR), Katie Peters (ODI; BRACED; CDKN), John Rees (Research Councils UK), Fabrice Renaud (UNU), Jakob Rhyner (UNU-EHS), Jane Rovins (Massey University; Disaster Reduction \& Resilience Solutions, Ltd), Paolo Ruti (WMO), Sahar Safaie (UNISDR), John Schneider (UNISDR STAG; GEM), Zita Sebesvari (UNU), Peijun Shi (State Key Laboratory of Earth Surface Processes and Resource Ecology, Beijing Normal University), Vitor Silva (GEM), Alanna Simpson (GFDRR; World Bank), Ram Babu Singh (IGU), Lucilla Spini (ICSU), Kaoru Takara (Disaster Prevention Research Institute, Kyoto University), Kimio Takeya (JICA), James Terry (College of Sustainability Sciences and Humanities, Zayed University), Frank Thomalla (SEI Asia Centre), Kathleen Tierney (Boulder Natural Hazard Centre; IRDR US NC), Peeranan Towashiraporn (Asian Disaster Preparedness Center), Joseph Trainor (Research Committee on Disasters of the International Sociological Association), Annisa Triyanti (Young Scientists Platform on DRR, UN MGCY), Kenichi Tsukahara (Kushu University), Yvonne Walz (UNU-EHS), Dennis Wenger (previously NSF), Irina Zoubenko-Laplante (UNESCO). 
Natural Disaster Prevention, Preparedness and Mitigation was adopted. ${ }^{1,2}$

A number of disasters, including Hurricane Mitch in 1998 and the 2004 Indian Ocean Tsunami, galvanized the international community to take action on disasters in a more comprehensive manner that included preparedness and recovery, broadening disaster management beyond response. One of the main policy outcomes was the Hyogo Framework for Action 2005-2015 ${ }^{3}$ (HFA).

Recognizing the importance of scientific and technical input for DRR policy and practice, the United Nations International Strategy for Disaster Reduction (UNISDR) established a Scientific and Technical Committee in 2008 and issued in 2009 the first biannual Global Assessment Report (GAR). Science was considered in its widest sense to include the natural, environmental, social, economic, health, and engineering sciences, and the term "technical" included relevant matters of technology, engineering practice, and implementation (UNISDR 2011, p. 35).

The 2009 Global Platform for Disaster Risk Reduction requested a broad strategic review of the state of the Hyogo Framework implementation. As part of this, the Mid-Term Review of the Hyogo Framework was published (UNISDR 2011) and the process was facilitated by the UNISDR Secretariat through a participatory approach involving stakeholders at international, regional, and national levels. A series of briefing papers was developed, which the UNISDR Scientific and Technical Committee-now the UNISDR Scientific and Technical Advisory Group (STAG)—was asked to contribute to.

The Mid-Term Review concluded that the implementation of the Hyogo Framework over the first 5 years had generated significant international and national political momentum and action for DRR and highlighted where further work was necessary to achieve the expected outcome of "substantial reduction of disaster losses, in the lives and in the social, economic and environmental assets of communities and countries" (UNISDR 2011, p. 69).

In the subsequent five-year period, there was increasing linkage with other policy areas including development, health, and climate change through the Global Platforms in 2011 and 2013 (WHO 2013). At the 2013 Global Platform, the wider importance of investment in DRR was demonstrated through an experimental simulation of long term macroeconomic impacts designed by the Japan International Cooperation Agency (JICA). The exercise was featured in the 2013 Global Assessment Report and helped to demonstrate the link between DRR and development issues such as the SDGs (UNISDR 2013).

\footnotetext{
${ }^{1}$ https://www.unisdr.org/who-we-are/history\#idndr.

2 https://www.unisdr.org/we/inform/publications/8241.

${ }^{3}$ https://www.unisdr.org/we/coordinate/hfa.
}

The Intergovernmental Panel on Climate Change (IPCC) in which UNISDR participated, through collaboration of their natural and social science working groups (I and II), generated the Special Report on Managing the Risks of Extreme Events and Disasters to Advance Climate Change Adaptation (IPCC SREX) (IPCC 2012). The report indicated increased evidence that climate change is affecting many natural and human systems and poses significant risks to human health, ecosystems, infrastructure, and agricultural production (IPCC 2012, 2014).

In the course of various national, regional, and international DRR meetings, the call for a stronger science element in DRR policy also received support through the Major Group on Science and Technology, organized by the International Council for Science (ICSU), and included many of the major science institutions of the world. The science, health, and technology call was maintained by the member states at negotiations held in Geneva in June 2014, November 2014, January and February 2015, and finally in Sendai, Japan in March 2015. Two influential papers (Alcántara-Ayala et al. 2015; Cutter and Gall 2015). Synthesized some of the major challenges emerging at this time, supporting the need for additional science and technology input in the Sendai Framework.

Other fora where "science-met-policy" allowing the scientific community, including STAG, to voice the science and technology input and contribute to shaping DRR policy included (Aitsi-Selmi et al. 2015):

(1) The Global and Regional Platforms for Disaster Risk Reduction, held biannually from 2007 to 2013, provided a forum for member states and other stakeholders, including the scientific community and civil society organizations, for information exchange, discussion of latest knowledge, and partnership building across sectors, with the goal to improve implementation of DRR through better communication and coordination amongst stakeholders.

(2) The Preparatory Committees for the post-2015 DRR Framework, open to governments and stakeholders (scientists, the private sector, civil society, intergovernmental organizations, and UN agencies), facilitated formal member state negotiations on the Sendai Framework. Three Preparatory Committee meetings were held between July 2014 and March 2015.

(3) Technical meetings such as the 2015 Tokyo Conference (outlined below) and thematic debates at the Global and Regional Platforms for DRR such as on the role of women and children in DRR, the health imperative for safer and resilient communities, and applying science and technology to policy and practice in DRR.

By the time the development of the successor to the Hyogo Framework was initiated, the need to widen the 
remit of DRR to activities beyond response to disasters had been identified. Efforts would now include detailed risk assessment, improving early warning and response capacities, impact-based forecasting, better resource management, knowledge creation and sharing, building public commitment, and developing supportive institutional frameworks. Challenges remained in the form of governance, capacity development, and financing among others (Shi et al. 2010; HSI 2011) as well as the need for stronger cross-linking to other policy agendas such as climate change and sustainable development (Schipper and Pelling 2006). The need for a more integrative DRR process that incorporates bottom-up and top-down actions, local scientific and technical knowledge, and a vast array of stakeholders was also clear (Gaillard and Mercer 2012). Programs such as the Integrated Risk Governance Project ${ }^{4}$ of the ICSU Future Earth program emerged to respond to the strong interest in improved risk governance systems expressed by UN member states in the United Nations International Strategy for Disaster Reduction.

Prior to the Third UN World Conference on Disaster Risk Reduction (WCDRR) in Sendai, the Tokyo Conference on International Study for Disaster Risk Reduction and Resilience $^{5}$ was held in January 2015. The Science Council of Japan, Integrated Research on Disaster Risk ${ }^{6}$ (IRDR), and the University of Tokyo along with UNISDR co-organized the conference with 400 participants from 27 countries in the presence of His Imperial Highness of Japan. The conference delivered the results in the form of the Tokyo Statement and Tokyo Action Agenda to raise global awareness on the issue of DRR, and built recognition of and foundation for the contribution of science and technology that was eventually incorporated in the Sendai Framework.

UN member states recognized that a stronger dialogue and collaboration of policymakers, practitioners, and the science and technology community from all geographical regions, all disciplines, and all local, national, regional, and international levels will support better DRR by identifying knowledge gaps, co-designing and co-producing knowledge, and making science more readily available and accessible to support DRR decision making on the ground. The Sendai Framework emphasizes the need to "enhance the scientific and technical work on disaster risk reduction and its mobilization through the coordination of existing networks and scientific research institutions at all levels and in all regions, with the support of the United Nations Office for Disaster Risk Reduction Scientific and Technical Advisory Group” (UNISDR 2015b, Paragraph 25g).

\footnotetext{
${ }^{4}$ http://www.irg-project.org/.

${ }^{5}$ http://monsoon.t.u-tokyo.ac.jp/AWCI/TokyoConf/en/.

6 http://www.irdrinternational.org/.
}

The Sendai Framework calls for better alignment of science and policy, ensuring DRR knowledge is "leveraged for the purpose of pre-disaster risk assessment, for prevention and mitigation and for the development and implementation of appropriate preparedness and effective response to disasters" (UNISDR 2015b, Paragraph 23). The Sendai Framework's numerous references to science call for a stronger understanding of disaster risks and root causes, access to reliable data at the scales where action needs to be taken, development of risk assessments and maps, including at local levels, long-term multi-hazard and solution-oriented research, strengthening scientific capacity to assess risks (including vulnerability and exposure), and interpreting and using risk information, as well as cooperation between scientists, policymakers, and stakeholders to support the science-policy interface through evidencedbased decision making.

Answering the call, UNISDR, with support from STAG, committed to establishing a Science and Technology Partnership that aims to meet the scientific objectives of the Sendai Framework. This requires mobilizing relevant institutions, networks, and initiatives from all levels and all regions to promote and improve dialogue and cooperation among scientific and technological communities, other relevant stakeholders, and policymakers in order to facilitate a science-policy interface for effective decision making in disaster risk management. The UNISDR Science and Technology Conference on the Implementation of the Sendai Framework for Disaster Risk Reduction 2015-2030 (henceforth referred to as the S\&T Conference) was convened in Geneva in January 2016, bringing together a diversity of scientists, practitioners, and policymakers in DRR.

\section{Conference Purpose and Design}

The S\&T Conference was one of the first large implementation conferences following the adoption of the Sendai Framework. The S\&T Conference had two main outcomes: (1) to launch the UNISDR Science and Technology Partnership for the implementation of the Sendai Framework; and (2) to discuss and endorse the UNISDR Science and Technology Road Map. The Science and Technology Road Map would define the aspirations and concrete commitments of the science and technology community over the 2015-2030 period to support the delivery of the science needed under each of the four Sendai Framework priority areas of action (particularly Priority 1: Understanding Risk), as well as ways to monitor progress and review needs.

The conference aimed to "bring together the full diversity of science and technology community, policy 
makers, practitioners and researchers from all geographical regions, at local, national, regional and international levels to discuss how the science and technology community will support the implementation of the Sendai Framework for Disaster Risk Reduction 2015-2030" (UNISDR 2015d, p. 1). The conference was designed to deliver a Road Map and Partnership, as well as commitments to concrete initiatives to support a comprehensive, multidisciplinary, evidence-based approach for DRR policy options and interaction with decision makers at all levels (UNISDR 2015e).

The six scientific functions identified by the Major Group on Science and Technology (Aitsi-Selmi 2015) were important in shaping the conference content and the Science and Technology (S\&T) Road Map. These are:

(1) Assessment of the current state of data, scientific knowledge, and technical knowledge on disaster risks and resilience (what is known, what is needed, what are the uncertainties, and so on);

(2) Synthesis of scientific evidence in a timely, accessible, and policy-relevant manner;

(3) Scientific advice to decision makers through close collaboration and dialogue;
(4) Monitoring and review of new scientific information and progress towards DRR and resilience building;

(5) Communication and engagement among policymakers, stakeholders in all sectors and in the science and technology domains themselves to ensure useful knowledge is identified and needs are met, and scientists are better equipped to provide evidence and advice;

(6) Capacity development to ensure that all countries can produce, access, and effectively use scientific information.

The conference was organized into four work streams and each work stream was divided into three working groups (Table 1). The main sessions were complemented with six side events on the dimensions of DRR that are of particular importance to the work of S\&T. The four conference work streams-particularly Work Streams 2 and 3-emerged to debate and articulate the scientific and technical activities required to deliver on Priority 1 of the Sendai Framework, including holistic, multi-hazard, impact-based, multidimensional risk assessment and the data needed to inform them. Work Streams 1 and 4 addressed cross-cutting themes of working in partnership and strengthening the science-

Table 1 Structure and purpose of the UNISDR S\&T Conference's core scientific content (http://www.preventionweb.net/files/45270_stcon ferencedraftprogrammecolor.pdf)

\begin{tabular}{|c|c|c|}
\hline \multicolumn{3}{|c|}{ Work streams (WS) and Working groups (WG) } \\
\hline Number & Title & Area addressed \\
\hline WS1 & $\begin{array}{l}\text { Scientific and Technical Partnership to Support the } \\
\text { Implementation of the Sendai Framework }\end{array}$ & $\begin{array}{l}\text { How the Partnership would leverage local, national, regional, and } \\
\text { international networks and platforms to advance }\end{array}$ \\
\hline WG1 & National and Local Level Networks and Platforms & multidisciplinary research and bring together science, policy, and \\
\hline WG2 & Regional Science and Technology Networks and Platforms & \\
\hline WG3 & Global Science and Technology Networks and Platforms & \\
\hline WS2 & $\begin{array}{l}\text { Understanding Disaster Risk, Risk Assessment, and Early } \\
\text { Warning }\end{array}$ & $\begin{array}{l}\text { How disaster risk is understood, how risks are assessed, and how } \\
\text { early warning systems are designed }\end{array}$ \\
\hline WG1 & Early Warning and Multi-hazard Monitoring & \\
\hline WG2 & Exposure and Vulnerability & \\
\hline WG3 & Risk Assessment and Management & \\
\hline WS3 & $\begin{array}{l}\text { Use of Science, Technology and Innovation Tools, Methods and } \\
\text { Standards to Support the Implementation and Reporting of the } \\
\text { Sendai Framework }\end{array}$ & $\begin{array}{l}\text { What data, standards, and innovative practices would be needed to } \\
\text { measure and report on risk reduction }\end{array}$ \\
\hline WG1 & Sharing Standards, Protocols, and Practices & \\
\hline WG2 & $\begin{array}{l}\text { Identifying Needs and Opportunities for Data Generation, } \\
\text { Synthesis, and Knowledge Management }\end{array}$ & \\
\hline WG3 & $\begin{array}{l}\text { Sharing Innovations to Improve Implementation and Reporting } \\
\text { of the Sendai Framework }\end{array}$ & \\
\hline WS4 & $\begin{array}{l}\text { Leveraging Science through Capacity Development and } \\
\text { Research }\end{array}$ & $\begin{array}{l}\text { What research and capacity gaps exist and how difficulties in } \\
\text { creating and using science for effective DRR can be overcome }\end{array}$ \\
\hline WG1 & Leveraging Science & \\
\hline WG2 & Capacity Development & \\
\hline WG3 & Research Gaps & \\
\hline
\end{tabular}


policy interface through capacity building, as well as aligning research and policy goals, including through highlighting important research gaps that need to be addressed to answer DRR policy needs (Table 1).

The side events were designed to highlight opportunities to develop ways of working to address particular inequalities and ethical and practical challenges. These were:

(1) Knowledge Hubs for DRR Science for the Implementation of the Sendai Framework;

(2) Science and Technology for Addressing Gender Inequality of Disaster Risk;

(3) Supportive Publishing Practices in DRR: Leaving No Scientist behind;

(4) The Role of Youth in the Application of Science for DRR;

(5) Bioethics and Ethics of Science and Technology in DRR;

(6) Research Funding for DRR.

\section{Taking Stock: Achievements, Challenges, and Opportunities in DRR Science}

Concept notes referred to in this section were developed by the Conference Organizing Committee and teams that included a wide range of experts and were used to inform discussions at the conference. Examples are given of existing initiatives to illustrate potential solutions for DRR. However, these examples are in no way exhaustive and reference to a particular initiative or organization does not constitute endorsement.

\subsection{Scientific and Technical Partnership to Support the Implementation of the Sendai Framework (Work Stream 1)}

Work Stream 1 (UNISDR 2016a) sought to discuss how to promote cooperation of DRR activity at all levels (local, national, regional, and global) by mobilizing existing networks and integrating DRR into development processes, identify research and technology gaps, and set recommendations for research priority areas in DRR, with the need to address emerging disaster risks, including technological and biological hazards. The guiding principle of the Sendai Framework is that effective DRR requires coordination and full engagement across scales and sectors to promote and support the availability and application of science and technology to decision making (UNISDR 2015b, Paragraph 19e).

Science networks and well-connected organizations strengthen the research-policy-practice nexus, and help to design targeted research to support specific policy issues. Research and practitioner networks that communicate well and disseminate their work avoid duplication and allow others to build on work that already exists. Networks can facilitate the effective communication and transfer of research outputs to policy stakeholders and conversely, enable policymakers to formulate and address specific questions and challenges to the scientific community. These science-policy interfacing mechanisms support ongoing dialogues involving "knowledge brokers" who support the co-development and co-production of knowledge (Meyer 2010; van Kerkhoff and Lebel 2015).

There is a clear recognition in the Sendai Framework that the existing national, regional, and global platforms for DRR have been mechanisms for coherence across agendas, and they have been important in mainstreaming DRR into other policies, and in monitoring and periodic reviews (UNISDR 2015b).

The Sendai Framework identifies networks as having a key role in accomplishing many of its goals, including: engagement (Paragraph 19e), knowledge sharing (Paragraphs $25 \mathrm{c}$ and 25d), integration and partnership working (Paragraphs 28b and 28c), innovation (Paragraph 31c), risk assessment (Paragraph 36b), supporting research and community action (Paragraph $36 \mathrm{~b}$ ), providing a sciencepolicy interface (Paragraph 36b,) and supporting thematic platforms (Paragraph 47c).

One of the biggest challenges to implementing the Sendai Framework is the limited knowledge of existing networks between scientific research institutions and their active role in DRR research, capacity development, and other technical services. Work Stream 1 sought to contribute to promoting knowledge of existing networks, organizations, and centers, as well as their structures, activities, and needs. Of particular interest was their cooperation frameworks and dialogues (if any) with policymakers at all levels. Needs for the following were discussed: (1) the importance of communication and dissemination of information by these networks and platforms; (2) linkages between these networks (local, national, regional, and global levels), as well as processes and mechanisms for engagement; and (3) how to strengthen the S\&T networks and link them to DRR platforms. The governance of this expanding system of networks and organizations with an impact on DRR will need to be examined to ensure a constructive, effective, and integrated multilevel DRR governance system that promotes co-design of policies and implementation (Shi et al. 2010; Corfee-Morlot et al. 2011).

\subsubsection{Local and National Networks and Platforms (Working Group 1)}

Local networks and institutions play an important role in producing and communicating science, which is context- 
specific, supporting the relevance and legitimacy in local communities. In comparison, national networks and platforms have the influence, scope, and resources to create a wider and deeper impact. It is critical for local organizations to be able to access and influence their national partners to ensure two-way coproduction of knowledge and dissemination and use of science (Jensen et al. 2015).

At the national level, many Organisation for Economic Co-operation and Development (OECD) countries are trying to integrate elements of anticipation in their risk management systems in terms of championing the integration of new knowledge and technology into DRR. Japan, for example, has made significant efforts towards integration by improving its earthquake preparedness systems, including through building code reform. Another example is the UK's emphasis on futures research through the method of horizon scanning that aims to use systematic studies of new developments in science and society to prepare for new risks.

National implementation plans underpinned by scientific evidence have the potential to target investment more accurately, contribute to greater resilience over the coming decades, and save lives (Calkins 2015). To achieve this, institutional capacity to learn from past disasters and integrate this into future preparedness policy is needed. Examples of institutional bodies with a "learning" capacity include the California Seismic Safety Commission ${ }^{7}$ and the relatively recent Organisation for Technical Investigation in Japan (OECD 2006).

A proposal suggested by the working group was for local universities to share knowledge, as well as facilitate local science-policy-practice partnerships and capacity building, including through local university consortia. The Japan Academic Network for Disaster Reduction, for example, was established in cooperation with the Science Council of Japan in January 2016 as a network of 48 academic societies related to DRR. The total number of members is approximately 246,000 across various disciplines. The network aims to match national development strategies with local needs. If local hubs of excellence can be championed, multidisciplinary research, including the behavioral and social sciences, could be promoted and applied and local knowledge that answers local needs and helps in pushing policy and practice to the "last one mile" (end-to-end) could be fostered. These hubs could act as bridges between levels and sectors and meet emergent policy needs required for effective response and to "Build Back Better."

The working group proposed recognized "national DRR science-policy councils/platforms" or a form of national focal points for science to support disaster risk

\footnotetext{
${ }^{7}$ http://www.seismic.ca.gov/.
}

management and meet the Sendai Framework recommendation for implementation. Developing focal points of scientific advice, for example through more extensive arrangements such as government chief scientific advisors at the national level, alongside national platforms for DRR, were also thought to be useful steps to strengthen the science-policy-practice intersection.

\subsubsection{Regional Networks and Platforms (Working Group 2)}

Regional networks can act as a link between global and local organizations; providing consistency, additional contextual information or data, and supporting public awareness. A number of advisory bodies provide scientific and technical advice at the regional level including regional networks, research or training centers, and regional branches of global networks. Other networks match subregional groupings, address particular hazards or create bridges to the private sector and development finance.

Most countries within these regions rely on these advisory structures for access to scientific evidence and advice to inform government, including parliamentary institutions. However, their exact roles, legitimacy, and impact at different administrative levels vary considerably, which can complicate transnational collaboration (OECD 2015). Across regions there is a need to strengthen coordination, cooperation, and knowledge exchange between networks to build on joint objectives and minimize duplication.

In Europe there are many such regional agencies providing scientific, policy, and technical advice, including the European Commission's Joint Research Centre ${ }^{8}$ (EC JRC). Other examples of the variety of bodies and networks include Partners Enhancing Resilience for People Exposed to Risks (PeriPeri U), ${ }^{9}$ ICSU regional branches, ${ }^{10}$ the African Centre for Disaster Studies, ${ }^{11}$ and the Asian Disaster Preparedness Center. ${ }^{12}$ In Asia, the UNISDR Regional Platform has established its own group on Science and Technology as part of the ISDR-Asia Partnership $^{13}$ to support the Sendai Framework. The Integrated Research on Disaster Risk ${ }^{5}$ (IRDR) has also begun setting up regional committees, starting in Latin America and the Caribbean.

The working group discussed the importance of engaging the end users of research at an early stage when working at regional level organizations, to ensure results

\footnotetext{
8 https://ec.europa.eu/jrc/.

${ }^{9}$ http://www.riskreductionafrica.org/.

${ }^{10} \mathrm{http}: / /$ www.icsu.org/.

11 http://acds.co.za/.

12 http://www.adpc.net.

13 https://www.unisdr.org/asiapacific/activities.
} 
are usable, and language and communications support users' practices. The group recommended establishing, empowering, and encouraging information sharing efforts among the networks of science and technology researchers at all levels (global, regional, national, and local).

\subsubsection{International Networks and Platforms (Working Group 3)}

Alongside regional bodies, transnational/international organizations can play an important role in both providing credible and trustworthy advice from different countries to national authorities and their policymakers, as well as authoritative information to other stakeholders such as the media and the general public (Jensen et al. 2015; OECD 2015). An important area of development could be to formally and informally recognize the links between DRR, development finance, sustainable development, and climate change to support their respective global communities of research, policy, and practice (Carabine 2015). An example of this in the climate change arena is the research outputs of the IPCC evidence and recommendations for action (IPCC 2012).

One of the international networks addressing DRR is the International Council for Science ${ }^{11}$ (ICSU), a nongovernmental organization with a global membership of national scientific bodies (122 members, representing 142 countries) and international scientific unions (31 members) with regional offices as well. The organization's aims are to identify and address major issues of importance to science and society; facilitate interaction amongst scientists across all disciplines and from all countries; promote the participation of all scientists; and provide independent, authoritative advice to stimulate constructive dialogue between the scientific community and governments, civil society, and the private sector.

The Integrated Research on Disaster Risk (IRDR) is a decade-long research program co-sponsored by ICSU, the International Social Science Council (ISSC), and UNISDR (ICSU 2008). The program addresses the shortfall in current research on how science is used to shape social and political decision making in the context of hazards and disasters by using an approach that integrates research and policy making across all hazards, disciplines, and geographic regions.

An opportunity exists across international fora for collaboration between networks from the broad range of sectors. Evidence reveals that this is an area that can have an influence on disaster risk, including urban development, transport, climate change, agriculture, healthcare, trade and so on. The differing purposes of these networks will need to be recognized by both scientists/technicians and policymakers and mutual ways forward will have to be negotiated at all levels.

The working group recognized the challenge of existing funding streams, institutional and organizational cultures in bridging policy sectors and scientific disciplines horizontally, as well as decision making levels vertically. It was recommended that strengthening and expanding existing infrastructures might be more effective than developing new ones. The working group also recognized the importance of international platforms in supporting data sharing, technology transfer, shared risk assessment methods, and global translation of scientific evidence.

\subsection{Understanding Disaster Risk, Risk Assessment, and Early Warning (Work Stream 2)}

The Sendai Framework set as one of its seven global targets to "substantially increase the availability of and access to multi-hazard early warning systems and disaster risk information and assessments to the people by 2030" (UNISDR 2015b, Paragraph 18g). The Sendai Framework highlights that disaster risk is multifaceted, comprising "vulnerability, capacity, exposure of persons and assets, hazard characteristics and the environment" (UNISDR 2015b, Paragraph 23) and that knowledge of risk should inform all elements of the disaster management cycle.

Work Stream 2 discussed concepts, methodologies, and global mapping such as the World Atlas of Natural Disaster Risk (Shi and Kasperson 2015) for understanding hazards and risk. The key dimensions of risk were highlighted, including exposure and vulnerability, the changing nature of risk over time, interacting hazards, and a holistic approach to risk assessment (Gill and Malamud 2014). The capabilities discussed would provide the scientific basis for delivering Priority 1 of the Sendai Framework (Understanding Disaster Risk) and be the key enablers to achieve progress for Priority 2 (Strengthening Disaster Risk Governance to Manage Disaster Risk). This goal will demand cutting-edge scientific methods and technological tools, integration and translation of scientific findings that are already available, and the fostering of a network of relationships at the science-policy-practice nexus (Shi et al. 2010; Corfee-Morlot et al. 2011).

\subsubsection{Early Warning and Hazard Monitoring (Working Group 1)}

Working Group 1 (UNISDR 2016b) focused on how to improve methods, tools, data, and communication systems related to early warning and hazard monitoring, and in particular on how to align the risk research agenda with the needs of modern DRR. A significant ambition of the Sendai 
Framework is the shift towards integrated (across sectors and scientific disciplines) and multi-hazard early warning systems linked with emergency communications mechanisms, social technologies, and hazard-monitoring telecommunications systems.

The wide-ranging need for and applications of hazard monitoring and early warning systems have led to the development of a number of programs and systems to provide these services and early warnings. Some have been facilitated by advances in remote sensing technology that have resulted in enormous improvements in space-based satellite systems for observing and disseminating information for early warnings for environmental, biological, technological, and natural hazards. Others are leveraging advances in computer technology, such as implementing internet portals to assist in assimilating and disseminating information from global to local levels to researchers, policymakers, and the public.

Enhanced technology, comprising real-time data collection and capability for modeling and dissemination of information, have given rise to warning systems that are becoming increasingly sophisticated and complex. These systems are able to incorporate greater scientific rigor, provide more accurate and detailed information, and disseminate more broadly to the population. Advances in computer simulation and modeling have made it possible to include information about the underlying hazards, as well as about the exposure and vulnerability of populations so that warning information can truly inform response. However, warning information needs to be appropriate to the timescale of the potential disaster, which can range from only minutes for a tsunami, to hours or days for extreme weather, and months to years for droughts or pandemics, and this is challenging (Foresight 2012).

Examples of global systems that enable sharing of early warning and hazard monitoring information include: The World Meteorological Organization Information System ${ }^{14}$ (WMO WIS); the Global Framework for Climate Services ${ }^{15}$ (GFCS) - a joint program of the World Meteorological Organization (WMO) and the World Health Organization (WHO); the Group on Earth Observations (GEO), which is dedicated to the application of earth observation information to a wide range of humanitarian needs; the United Nations Platform for Space-based Information $^{16}$ for Disaster Management ${ }^{17}$ and Emergency $^{18}$ Response $^{19}\left(\mathrm{UN}-\mathrm{SPIDER}{ }^{20}\right)$; the International

\footnotetext{
14 http://www.wmo.int/pages/prog/www/WIS/index_en.html.

$15 \mathrm{http}: / / \mathrm{www} . \mathrm{gfcs}-\mathrm{climate} . \mathrm{org} /$.

${ }^{16} \mathrm{http}: / /$ www.un-spider.org/node/7682.

17 http://www.un-spider.org/node/7661.

18 http://www.un-spider.org/node/7670.

19 http://www.un-spider.org/node/7680.
}

Health Regulations (IHR) (2005) (WHO 2008b); the FAO Global Information and Early Warning System ${ }^{21}$ (GIEWS), which was established in the wake of the world food crisis of the early 1970s and provides information on food production and food security; and the UNESCO Intergovernmental Oceanographic Commission Tsunami Programme (UNESCO 2015).

Examples of emerging multi-hazard early warning systems at regional and national levels include: the European Flood Awareness System ${ }^{22}$ (EFAS) and the European Forest Fire Information System ${ }^{23}$ (EFFIS); the Global Disaster Alerts and Coordination System (GDACS), developed by the European Commission Joint Research Centre (EC JRC) and used jointly by the European Union (EU) and the UN; and the Natural Hazards Partnership (NHP) Daily Hazard Assessment. ${ }^{24}$

Critical to the success of any warning system is communication. Following the 2004 Indian Ocean Tsunami that killed about 230,000 people, Indian Ocean countries developed a number of warning systems coordinated through the United Nations Educational, Scientific and Cultural Organization Intergovernmental Oceanographic Commission Tsunami Programme (UNESCO 2015). This system of warning centers incorporates the latest in advanced detection, analysis, and communication technology, and has issued warnings for a number of potentially damaging events. However, it has been criticized for falling short "in the last mile" (Witze 2014), resulting in the failure of communities to respond appropriately to the danger at hand. This issue is being addressed through the concept of people-centered early warning systems, which comprise four elements: risk knowledge; monitoring and warning services; dissemination and communication; and response capabilities (UNISDR 2009). Developing successful communication systems requires extensive preparation, including an understanding of how to enable communities to respond effectively (Pearce 2003). Where possible, the resulting applications should deliver early warning information products through the use of simple, low-cost equipment and facilities and should be delivered across as many dissemination and broadcasting channels as possible.

Under discussion by the working group was the need to identify whether the capacities for implementing early warning systems in different countries and regions remain highly varied. Least developed countries (LDCs) and small island developing states (SIDS) are particularly susceptible

\footnotetext{
${ }^{20} \mathrm{http} / / / \mathrm{www}$. un-spider.org/about/what-is-un-spider.

${ }^{21} \mathrm{http}: / / \mathrm{www}$. fao.org/giews/english/index.htm.

22 https://www.efas.eu/.

${ }^{23} \mathrm{http}$ ///forest.jrc.ec.europa.eu/effis/.

${ }^{24}$ http://www.metoffice.gov.uk/nhp/daily-hazard-assessment.
} 
to weaknesses in their ability to issue critical warnings (UNDP 2004; UNISDR 2006).

The importance of effective partnerships at international, regional, national, and local levels to ensure involvement and ownership of warning systems was highlighted. If communities are not engaged as main actors in the production and dissemination of warning systems, the components, communications systems, and usage methods of warning systems cannot be appropriately designed. User voices from across society should be integrated, including those of vulnerable populations such as young people, as well as community representatives to provide public legitimacy. If warnings are not acted upon, they are not helpful in preventing loss. This means feedback loops should be designed into systems and the message that "prevention saves lives" should be reinforced.

\subsubsection{Exposure and Vulnerability (Working Group 2)}

The Sendai Framework promotes a people-centered approach and the use of a participatory process in decision making that responds to the needs of users and is sensitive to social and cultural aspects, gender, and age. Working Group 2 (UNISDR 2016c) addressed ways to promote a common understanding of exposure ${ }^{25}$ and vulnerability ${ }^{26}$ as key dimensions of risk alongside hazard probability. The severity of the impacts of a disaster depends strongly on the level of exposure and vulnerability (Terry and Goff 2012) in the affected area. Evidence indicates that overall risk has increased worldwide, largely due to increases in the exposure of persons and assets and possibly increases in inequality, which is a shaper of vulnerability, thus calling for greater attention to these dimensions of risk.

Both exposure and vulnerability are dynamic, vary across temporal and spatial scales, and depend on economic, social, geographic, demographic, cultural, institutional, governance-related, and environmental factors. Moreover, factors affecting exposure and vulnerability vary considerably by hazard context, disaster stage, and national setting (Rufat et al. 2015). High exposure and vulnerability are linked to skewed development processes, such as those associated with environmental mismanagement, rapid demographic changes, rapid and unplanned economic processes, urbanization in hazardous areas, poor governance, and the scarcity of livelihood options for people, particularly the poor (IPCC 2012). Inequality also

\footnotetext{
$\overline{25}$ Exposure is defined as the "people, property, systems, or other elements present in hazard zones that are thereby subject to potential losses" (UNISDR 2009, p. 15).

${ }^{26}$ Vulnerability is defined as "The characteristics and circumstances of a community, system or asset that make it susceptible to the damaging effects of a hazard" (UNISDR 2009, p. 30).
}

affects response and coping mechanisms, putting more people at risk.

Increasing exposure, for example, has been the major cause of long-term increases in economic losses from weather-related disasters (IPCC 2012). There have been localized reductions in vulnerability as a result of better building standards and compliance, for example, but these reductions are geographically uneven and there are many instances of increased vulnerability, particularly in large urban centers and in developing countries. This has created new risk and a rise in disaster losses, particularly at the local and community levels, with the poor and marginalized, minority populations, women and children, and those dependent on single-sector economies disproportionately affected (Cutter et al. 2003; UNISDR 2015a).

To assess whether something has changed it needs to be measured. Efforts to quantify risk have typically considered a limited number of dimensions like the physical dimension (for example, buildings and mortality) and economic aspects of vulnerability, but social vulnerability is poorly understood and difficult to measure. Measuring vulnerability and exposure requires an integrated understanding of components and how these factors combine to contribute to the resilience ${ }^{27}$ of communities (Carreño et al. 2007; Burton and Silva 2014). These approaches include methods that use predominantly statistical data gathered from published sources, and approaches that involve surveying local populations. Additional useful approaches exist, such as examining vulnerability and its relationship to inequality in the social and health sciences [see the social determinants of health approach (WHO 2008a)].

In most countries, vital statistical information is collected through a national census, but this information seldom incorporates information on the construction of buildings, or social demographic data vital to assessing the vulnerability of populations. Moreover, this type of statistical data is often only available at a level of geographic aggregation that makes it difficult to use effectively in risk assessments. Issues also include access to proprietary data, privacy, accuracy, consistency, and lack of openness.

Significant advances have been made in using many sources of statistical data to develop exposure models. However, the development of exposure databases that are fit for the purpose of risk assessments across geographic scales and for different hazards and types of risks represents a significant challenge. This is compounded by the fact that exposure data is multifaceted and complex and

\footnotetext{
$\overline{27}$ Resilience is defined as "the ability of a system, community or society exposed to hazards to resist, absorb, accommodate to and recover from the effects of a hazard in a timely and efficient manner, including through the preservation and restoration of its essential basic structures and functions" (UNISDR 2009, p. 24).
} 
seldom, if ever, the responsibility of any one organization to collect and maintain.

An important area of research is the development of exposure databases from remote sensing satellites and computer-based techniques such as crowd-sourcing and drones that can provide highly accurate descriptions of population distributions and physical attributes of the natural and built environment. Such approaches are even more powerful when combined with ground-based data from imagery or statistical data.

The working group recognized the importance of incorporating key markers of socioeconomic vulnerability and resilience into risk assessment data and models that are quality-controlled by uniform standards. There is a role for international organizations to develop and promote these, for example the Global Facility for Disaster Reduction and Recovery $^{28}$ (GFDRR), the ICSU Integrated Research on Disaster Risk ${ }^{29}$ (IRDR), and the Global Earthquake Model $^{30}$ (GEM).

\subsubsection{Risk Assessment and Management (Working Group 3)}

Working Group 3 (UNISDR 2016d) addressed the use and advancement of methods for "fit for purpose" risk assessments that inform risk management plans. To improve DRR, risk assessments should support better risk management, defined (UNISDR 2009, p. 26) as "the systematic approach and practice of managing uncertainty to minimize potential harm and loss." Disaster risk management then follows as implementation of policies, processes, and actions to prevent new risk, reduce existing disaster risk, and manage residual risk, all of which contribute to the strengthening of resilience. However, disaster risk is increasingly understood to be complex and multifaceted (involving hazard, exposure, vulnerability, and capacity), with interdependencies that may be overlooked and cause cascading effects over time and space (Gill and Malamud 2014, 2016).

The ability to assess risk using a multi-hazard approach in a timely, technically sound, and easily communicated fashion is the foundation to develop the necessary understanding by key stakeholders tasked with managing and reducing disaster risk. Performing these assessments at any scale-local (individual, neighborhood, and community), national, regional, or global-requires considerable expertise, time, and resources. Risk assessment methods frequently cite the following challenges:

\footnotetext{
${ }^{28}$ https://www.gfdrr.org/.

29 http://www.icsu.org/what-we-do/interdisciplinary-bodies/irdr.

$30 \mathrm{http}: / / \mathrm{www}$.globalquakemodel.org/gem/.
}

(1) Methods are largely confined to a single hazard, with little or no ability to aggregate risks from different threats/hazards. A multi-hazard approach will require data and methods to assess, model, and plan for both multiple hazards in the same location and cascading hazards across all disciplines (Gill and Malamud 2014). As the Sendai Framework explicitly covers biological and technological disasters alongside natural hazards, that is, takes an "all hazards" approach (UNISDR 2015b, Paragraph 24j), methods from other sectors will be useful in strengthening DRR science and methodologies.

(2) Methods are often variable (non-standardized), resulting in a lack of transparency of understanding of uncertainty, and of scientific rigor necessary for publication, and thus replication by other scientists. Most importantly it hampers risk communication and use of the results by decision makers. Risks may also be measured on a subjective scale (moderate, high, very high) that makes comparison and evaluation of cost-effectiveness and resource allocation difficult.

(3) Risk assessments are frequently performed without the engagement of all relevant stakeholders at the outset and without sufficient communication and dissemination upon completion.

The quality of risk assessments relies to a significant extent on the quality and availability of data. Although access to data sources for disaster-related events and impacts are often limited, sources exist and are improving. Quality, coverage, and availability of data and methodologies for risk modeling are discussed in Work Stream 3 below. New methodologies and integrated approaches are being developed to visualize, model, and assess risk across cascading hazards and multiple hazards (for example, Gill and Malamud 2014; Zhou et al. 2015). The working group reiterated the need for open, credible, reliable data, as well as the need to make the path from science to data faster for information to be usable and used. The working group acknowledged the need to develop guidelines to integrating risk assessments into strategic planning that were addressed further by Work Stream 3.

Once risk assessments are available, their uptake and use requires effective communication and dissemination to leverage the results and ensure that risk information is useful, usable, and used (Aitsi-Selmi et al. 2015). The working group recognized the importance of developing outputs that are understandable by decision makers. A particular challenge is to communicate the policy concept of "acceptable risk" and for this type of new concept to be accepted across organizational, sectoral, and governance boundaries. 


\subsection{Use of Science, Technology, and Innovation Tools, Methods, and Standards to Support the Implementation and Reporting of the Sendai Framework (Work Stream 3)}

The Sendai Framework defines seven precise global targets that will require adequate data and information to support monitoring through quantitative and qualitative indicators. An opportunity exists for joint monitoring across the major international development agreements that were adopted in 2015 and 2016 to make use of the overlap and synergies and avoid duplication (ODI 2013).

Work Stream 3 aimed to highlight and share practical solutions for data and risk assessment related issues as well as research and governance challenges for collecting and reporting on losses from disasters. Relevant recommendations in the Sendai Framework under Priority 1 include, at the national and local levels, promoting "the collection, analysis, management and use of relevant data and practical information and ensure its dissemination" (UNISDR 2015b, Paragraph 24a); promoting "real time access to reliable data, make use of space and in situ information, including geographic information systems (GIS)" (UNISDR 2015b, Paragraph 24f); and, at the global and regional levels, enhancing "the development and dissemination of science-based methodologies and tools to record and share disaster losses and relevant disaggregated data and statistics" (UNISDR 2015b, Paragraph 25a).

Analyses of the Hyogo Framework reporting mechanisms revealed a number of limitations of the Hyogo Framework Monitor as a tool for measuring and reporting progress in DRR (Ishigaki and Mochizuki 2014; UNISDR 2014). Systems of data and indicators to be used for monitoring progress until 2030 must strive to overcome the challenges of the Hyogo Framework Monitor, including the standardization of methodologies for risk modeling and data generation. Alongside the Sendai Framework recommendations, the OECD also encourages the development of standardized accounting frameworks for expenditure on DRR and disaster losses in order to evaluate the economic benefits from their disaster risk investments (OECD 2014).

A common terminology is an important starting point for this. A revision of the 2009 UNISDR terminology (UNISDR 2009) was recommended in the Sendai Framework through the establishment of an Intergovernmental Open Ended Working Group on Indicators and Terminology. Expert consultations have taken place in partnership and cooperation with STAG and its members and the European Commission Joint Research Centre ${ }^{9}$ (EC JRC) (UNISDR 2015c). This working group expects to complete its objectives by the end of 2016. Another development in this area is the IRDR Peril Classification and Hazard Glossary $^{31}$ (IRDR 2014).

\subsubsection{Sharing Standards, Protocols, and Practices (Working Group 1)}

The conference recognized that the Hyogo Framework contributed both directly and indirectly to stimulating science and technology applications related to DRR (UNISDR 2016e). However, significant discrepancies exist within and between regions and countries, as well as within countries. High-income countries tend to have better practices and resources that could be shared with lower-income countries, including through common standards and protocols. Risk assessments rely on good exposure, vulnerability, and hazard data with accuracies that need to be adequate for the scale of analysis. Global risk models need to be consistent in time and space. At the regional level, risk models rely on exposure datasets that are rarely standardized, or have adequate detail over the entire area of interest. At the local level risk models and hazard datasets lack spatial detail required to capture the underlying drivers, and loss data lack good geospatial referencing, which makes comparability and analysis difficult over time and space (Cutter and Gall 2015).

The Global Assessment Report (GAR) is an example of emerging coordinated assessment and reporting (UNISDR 2009, 2011, 2013, 2015a). Areas of DRR that could be enhanced by common and transparent methodologies include standards on hazard, vulnerability, and risk assessment of various assets, codes and standards for engineering design and construction of various infrastructures, guidelines and methodologies for retrofitting of various structures, hazard monitoring and early warning systems instrumentation, and so on. Emerging standards and protocols (such as the EU Risk Management Capability Assessment Guidelines ${ }^{32}$ ) must be shared and further developed. Multi-hazard risk calculation platforms can support standardization through common software (Daniell et al. 2014), and are used in the Indian Ocean, Southeast Asia, and West Africa and has been used for the Global Risk Assessment (217 countries) that supports the UNISDR GAR13 (UNISDR 2013) and GAR15 (UNISDR 2015a).

The development of guidelines (and standards) of good practice in risk assessment could borrow from methodologies in other sectors such as from the internationally renowned UK National Institute of Health and Care

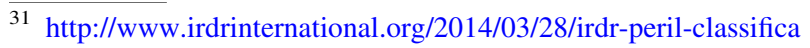
tion-and-hazard-glossary/.

32 http://eur-lex.europa.eu/legal-content/EN/TXT/?uri=CELEX\% 3A52015XC0808(01).
} 
Excellence $^{33}$ which has developed well-respected and transparent methodologies for technology and clinical practice assessments. Users and experts are invited to design and deliver cost-effectiveness evaluations that are used for frontline practice and national policy and only recommend technologies and practices that fall below a pre-agreed cost-effectiveness threshold.

The standardization of data, particularly loss data, is progressing slowly and few open sources of loss data are suitable for spatial and temporal comparisons. The GAR13 (UNISDR 2013) and GAR15 (UNISDR 2015a) have shown that more accurate measurements reveal $50 \%$ more losses than previously accounted for. The standardization of loss data collection has been promoted by UNISDR through expanding the methodologies of DesInventar, ${ }^{34}$ originally developed and launched in the Latin America and Caribbean (LAC) Region, to other countries and regions. DesInventar aims to fill the gap in data at lower administrative levels, and to give visibility to small-scale disasters. The EU has published guidelines on sharing disaster loss and damage data for assets (De Groeve et al. 2013; Corbane et al. 2015) and the Centre for Research on the Epidemiology of Disasters ${ }^{35}$ (CRED) has been maintaining an Emergency Events Database ${ }^{36}$ (EM-DAT) that helps to record human losses.

The Sendai Framework is an opportunity for renewed cooperation with standards organizations, such as the International Organization for Standardization (ISO) and the International Electrotechnical Commission (IEC), and to align disaster risk standards with existing professional standards, some of which were listed in the concept note for this working group (UNISDR 2016e). ${ }^{37} \mathrm{~A}$ role for national statistical offices (NSOs) and specialized technical agencies in ensuring capacity and capability may exist to collect and process data, but very few countries use NSOs for DRR purposes. In the Asia-Pacific region, the UN Economic Commission for Europe (UNECE) and the UN Economic and Social Commission for Asia and the Pacific (UNESCAP) statistical committee are playing leading roles in this area.

In terms of indicators for risk assessment and monitoring, the private sector has been developing industry standards on risk assessment and financing for decades including metrics such as Annual Average Loss and Maximum Probable Loss, but these metrics are not widespread in the public sphere. The conference recognized that

\footnotetext{
33 https://www.nice.org.uk/.

34 http://www.desinventar.org/.

35 http://www.cred.be/.

36 http://www.emdat.be/.

37 http://www.unisdr.org/partners/academia-research/conference/ $2016 /$.
}

this was a challenge and more collaboration between public and private sectors on this was needed. Other examples include the indicators for disaster risk and risk management of the Inter-American Development Bank (IDB) used by 26 national governments and the IDB country risk profiles, which cover most countries in the Americas (Cardona and Carreño 2013).

\subsubsection{Identifying Needs and Opportunities for Data Generation, Synthesis, and Knowledge Management (Working Group 2)}

The broadening of the scope of the Sendai Framework beyond natural hazards to a multi-hazard approach is a key opportunity for the DRR community in terms of data and knowledge management (UNISDR 2016f). Successful generation of a knowledge base to inform the multi-hazard approach, which incorporates technological and biological hazards, will require the integration of existing databases and methodologies for data collection and synthesis. Updating and designing new standards and protocols will be part of the process as discussed above.

For example, multi-hazard disaster loss accounting for monitoring the Sendai Framework requires quantitative socioeconomic and physical data, as well as qualitative information that can support DRR governance (Shi et al. 2010; Corfee-Morlot et al. 2011). DRR loss databases could be combined with exposure, hazards, and vulnerability databases and become risk modeling databases. Epidemiological databases used for monitoring and surveillance of disease and mortality could be linked to spatial databases for improved analysis, reporting, and dissemination of disaster impacts. Working across disciplines, health professionals could be more actively engaged to enable the use of health outcomes (including mortality, injury, and mental health outcomes) (Murray 2014). Risk modeling databases will need to integrate local and indigenous knowledge and be used for promoting community engagement in data analysis, communication, and dissemination. This will increase the awareness of communities, policymakers, and the exposed public at large.

The working group recognized that challenges were present in that loss data are not consistently collected with the level of detail required for accurate reporting, and sources are often non-validated. Nationwide loss data are typically collected by public institutions, while global loss data are held and maintained by reinsurance companies for commercial purposes and by academic institutions for research purposes. However, the new scope was seen as an opportunity to foster dialogue across disciplines and sectors that inform multi-hazard DRR systems and find opportunities to align the various objectives and interests. 
Due to the different policy objectives, discussions on standards for loss and risk data focus on different elements in the Sendai Framework, SDGs, and climate change frameworks. The Sendai Framework focuses on measuring disaster losses (including number of those dead, injured, and affected, as well as economic losses, and disruption). The SDGs focus on an extremely broad set of development objectives and, in terms of disaster losses, on being sensitive to vulnerabilities by gender, age, and disability. The climate change community focuses on trends in losses and the anthropogenic causes of hazards and future impact scenarios. An opportunity exists in aligning these frameworks and their monitoring mechanisms and capitalizing on the close links, including between climate change adaptation and DRR.

\subsubsection{Sharing Innovations to Improve Implementation and Reporting of the Sendai Framework (Working Group 3)}

The need to bridge the gap between scientific knowledge and decision making by actively assisting governments in the uptake and use of scientific knowledge, including technological innovations, is among the key lessons learned from the implementation of the Hyogo Framework (UNISDR 2016g). Capitalizing on the wealth of existing scientific knowledge to improve the accessibility and uptake of research results for operational activities-particularly for a multidisciplinary, multi-sectoral, and international field like DRR - requires mechanisms for sharing innovations and enhancing uptake. These include innovative ways of collaborating; conceptualizing risk; creating, storing, and sharing data, for example, through crowd sourcing; and co-designing and co-producing research with stakeholders.

Knowledge centers, specifically designed to pool research results, translate them into actionable information, and build networks across disciplines, are essential instruments for the science-policy interface. New initiatives, such as the European Commission Disaster Risk Management Knowledge Centre ${ }^{38}$ (EC DRM-KC) or the Global Centre for Disaster Statistics at Tohoku University ${ }^{39}$ are examples.

New methodologies of recording, organizing, and storing data and of reporting supported by geospatial technologies should be considered. Technologies include Geographical Position Systems (GPS); Geographic Information Systems (GIS); Earth Observation (in situ and

\footnotetext{
38 http://drmkc.jrc.ec.europa.eu/.

39 http://www.undp.org/content/undp/en/home/presscenter/pressre leases/2015/03/15/undp-and-tohoku-university-launch-global-centrefor-disaster-statistics-.html.
}

remotely sensed); and hand-held portable devices in support of crowd sourcing. These can provide a number of advantages, including increased precision of disaster risk information; facilitation of data sharing and organization; increased speed of reporting and data availability for decision making and research; and supporting standardization. However, the use and maintenance of such technologies and methods to ensure quality control requires capacity building.

Disaster risk is the product of risks arising from an increasingly interdependent economy with cascading effects that can have a multiplying effect on losses. Risk modeling and disaster impact assessments should incorporate wider risk drivers and disaster impacts. Innovating in conceptual ideas to strengthen the theoretical framework informing a holistic approach to risk could help in organizing information and the design of an integrated DRR database by making sense of direct and indirect loss data. The Social Determinants of Health Framework (CSDH 2008) assesses the true risk and impact of interventions and policies, recognizing that immediate health risks are embedded in a complex web of wider socioeconomic factors. A framework like this might further inform disaster risk assessment.

The working group recognized that community-based innovation and practices play a significant role in improving the dialogue and partnership between vulnerable communities and other actors in DRR, including government authorities, nongovernmental organizations (NGOs), international agencies, academia, and the private sector. A key challenge is how to provide appropriate conditions that allow for the up-scaling of successful community innovations, including their incorporation into the policy-making process. Opportunities lie in the power of new information and communication technology (ICT) tools and applications. Examples of community mobilization initiatives include Ushahidi, the Humanitarian OpenStreetMap Team (HOT), and Twitter (Kawasaki et al. 2013).

\subsection{Leveraging Science Through Capacity Development and Research (Work Stream 4)}

Fifteen years ago, hazard researchers explicitly stated that improved knowledge was not sufficient by itself to reverse the upward trend in disaster losses, and called into question how knowledge is used (White et al. 2001). Despite an immense expansion of risk-related knowledge systems including special research programs and institutes, specialized journals, advanced technology and increased financial resources, converting research findings into concrete applications for DRR and management remains a challenge (Weichselgartner and Kasperson 2010). This has raised questions about barriers in the science-policy- 
practice nexus that hinder the effective use of existing knowledge to make it useful, usable, and used (Aitsi-Selmi et al. 2015).

One of the Sendai Framework Priority 1 recommendations is "To promote and improve dialogue and cooperation among scientific and technological communities, other relevant stakeholders and policymakers in order to facilitate a science policy interface for effective decision making in disaster risk management" (UNISDR 2015b, Paragraph 24h). It also encourages the diversity of DRR stakeholders to "support the interface between policy and science for decision-making" (UNISDR 2015b, Paragraph 36b).

The call reflects the emphasis throughout the negotiation process of the Sendai Framework on the need to integrate science and technology into decision making, as heard in statements from member states, intergovernmental organizations (IGOs), and thematic Major Groups (UNISDR 2015b). However, important challenges exist for those tasked with translating evidence into information for decision making. Because research and applied activities often have fundamentally disparate purposes and respond to the needs of very different audiences they can lead to different world views and can make translation and uptake of evidence difficult (Quarantelli 1993).

Furthermore, the Sendai Framework promotes a multihazard approach that encompasses natural, biological, and technological hazards. Technological hazards that can cascade as a result of system interdependence demonstrate the need for cooperation across physical, conceptual, and imagined boundaries.

Reconnecting science with policy and practice is considered by some to be among the first tasks in implementing the Sendai Framework (Pearson and Pelling 2015). Since an implementation plan is underpinned by scientific evidence, it has the potential to target investment more accurately and reduce disaster losses, including saving lives (Calkins 2015). This work stream discussed ways of overcoming these challenges to increase the relevance of science for decision makers and streamline DRR into all policies. Specific opportunities for leveraging science were discussed, including aligning incentives in scientific and policy systems, and the points raised reflected more indepth discussions in Work Streams 1, 2, and 3 on specific areas of DRR.

\subsubsection{Leveraging Science (Working Group 1)}

It is not entirely clear why the wealth of scientific findings does not find its way into policy. The working group discussed possible reasons (UNISDR 2016h): (1) knowledge is incomplete; (2) data is available but not translated into usable knowledge; (3) knowledge is used effectively but takes a long time to take effect; or (4) knowledge is used effectively in some respects but is overwhelmed by increases in population vulnerability and size (Weichselgartner and Kasperson 2010). The Hyogo Framework implementation period saw a number of new initiatives to address these barriers:

(1) Development of data synthesis and presentation tools such as climate forecasting and sophisticated earth observation tools;

(2) Centralization of DRR information in online repositories for use by both decision makers and researchers such as PreventionWeb; ${ }^{40}$

(3) Use of open access online platforms to make evidence easily available for humanitarian emergencies (such as Evidence Aid) $;{ }^{41}$

(4) Mainstreaming of DDR and climate change adaptation in country development strategies was established (such as the Global Facility for Disaster Reduction and Recovery ${ }^{42}$ (GFDRR).

UNISDR publishes regular S\&T reports through the STAG and, with these, a number of case studies from around the world and from different scientific disciplines have been made available to illustrate how science is used in DRR. More than 50 case studies are available online and include Flood Risk Reduction in the Netherlands: The "Room for the River" project ${ }^{43}$; building resilience to earthquakes in Chile ${ }^{44}$; and an earthquake early warning system for Japanese bullet trains. ${ }^{45}$

An example of successful intergovernmental evidencetranslation, which is multidisciplinary and brings together different communities of policy and practice, is the IPCC SREX (IPCC 2012). For DRR, such a science-policy platform has yet to be established and the real challenge is to harmonize all related processes to avoid inefficiency and overlapping in such a mechanism.

There is an opportunity to learn lessons from existing international and regional initiatives to coordinate scientific efforts in DRR and interface with policy at a high level such as STAG, which facilitates contact with the scientific community as key to supporting DRR decision-making; and the recently launched European Commission Disaster Risk Management Knowledge Centre (EC DRM-KC). The DRM-KC aims at facilitating access to relevant knowledge

\footnotetext{
$\overline{40} \mathrm{http}: / / \mathrm{www} \cdot$ preventionweb.net/english/.

41 http://www.evidenceaid.org/.

42 https://www.gfdrr.org.

${ }^{43}$ http://www.preventionweb.net/files/workspace/7935_casestudy6. pdf.

44 http://www.preventionweb.net/files/workspace/7935_casestudy 10. pdf.

${ }^{45}$ http://www.preventionweb.net/files/workspace/7935_casestudy4. pdf.
} 
and translating scientific data into actionable disaster risk information at the local, national, European, and global levels. Similar initiatives and partnerships should be encouraged and supported for improving the dialogue at the science-policy practice nexus making. The Disaster Management Center of the South Asia Association of Regional Cooperation ${ }^{46}$ (SAARC) is an example of a platform of influence for science within a group of countries that cover a large section of the world population in low- and middle-income countries. A significant recommendation from the working group's discussion was to build on the regional and international platforms and current programs, such as those of ICSU's IRDR to build national scientific advisory capacity.

The Overseas Development Institute (ODI) has a dedicated program-Research and Policy in Development-to improve the integration of local knowledge and researchbased evidence into policy making by working with researchers, think tanks, civil society, donors, and governments. In supporting decision makers in the use of scientific findings, an alternative to workshops is other forms of experiential learning, like "policy-gaming" (CDKN 2012). Conversely, in encouraging researchers to respond to policy needs, applicants for research grants could be required to provide evidence that their research is in demand from decision makers (Jones 2012).

This working group recognized that most current systems for incentivizing and evaluating academics are often incompatible with policy and practice needs. They can discourage the integration of research across disciplines, inhibit the use of diverse forms of knowledge and information (for example, indigenous knowledge), and minimize engagement with decision maker priorities. Academic success is often measured by the number of peer-reviewed journal articles, while shorter nontechnical outputs like policy briefs, blogs, and other forms of grey literature are rarely recognized or rewarded (Jones 2012; Trainor and Subbio 2014).

\subsubsection{Capacity Development (Working Group 2)}

Crucial to implementing the Sendai Framework is the need to purposefully advance multidisciplinary DRR research in line with disaster risk capacity building for both decision makers and professionals/practitioners. Such formal capacity-building processes can leverage existing global experience in disaster risk related training and education, especially efforts that are culturally coherent and contextually nuanced. The cultural context of countries and local communities needs to be integrated in capacity development initiatives alongside inclusiveness as an important

\footnotetext{
$\overline{46}$ http://www.saarc-sec.org/.
}

guiding principle. The Sendai Framework makes extensive reference to the delivery of culturally sensitive and inclusive DRR related activities (UNISDR 2016i).

A challenge exists in the substantial disparities in capacity development for science in the disaster risk management field globally. There is a heavy dependence on international organizations and associated experts in developing countries and limited South-South cooperation. Furthermore, there has been a historic focus of extractive research (especially in Africa) by institutions in the global north, with disaster/humanitarian data repositories remaining located in international agencies (rather than the national institutions of the countries where the data originated).

Education in DRR is at the heart of a sustainable capacity development system. Such a system reflects a growing recognition that a well-educated population is essential for a "productive, prosperous and resilient country" (Group of Eight 2013, p. 7). Work on mainstreaming DRR in primary school curricula has already been mapped and guidelines developed and published. However, further work is needed for greater quality assurance and using opportunities at the tertiary level to strengthen DRR as an important area of research and teaching.

Low levels of education in many countries also deter progress in implementing multidisciplinary tertiary level learning programs in areas that address emerging risk and resilience. While progress in higher education capacity building efforts for integrated disaster risk research has advanced encouragingly in recent years (especially in Africa), these efforts have been neither supported financially by educational foundations, nor the science and development communities. Progress in DRR practice is significantly strengthened by informed, multidisciplinary, applied risk education at tertiary levels. Yet, the societal imperative for skilled capacity in practice often conflicts with academic promotional requirements for research performance.

The emergence of transnational knowledge consortia and academic networks (see Work Streams 1 and 3) that can transcend disciplinary and geographic boundaries allows for a wider scope of disaster risk knowledge transfer and capacity building. Additional opportunities for strengthening capacity include increasing collaboration with the private sector and mechanisms for technology transfer.

Globally, there is an uneven application of minimum qualification criteria for government officials working in disaster risk related fields. This irregularity has led to the appointment of government officials with highly varied backgrounds, many with limited formal science training or education-effectively constraining governmental demand for robust risk research and associated capacity building. 
Past experience in disaster risk management capacity building underlines the importance of training the trainers at national and local levels. With risk communication often constrained by language barriers, there is scope for exploring the role of technology in better enabling the translation and interpretation of training materials into different languages, including local dialects and in culturally appropriate ways. Specific content areas for training include instruction on national disaster loss databases, national and local risk profiles, city resilience benchmarking, including scorecards, national and local targets and indicators, elements of pre-disaster recovery planning to Build Back Better, development of national and local strategies and plans, forecasting, modeling, and manipulating the data to inform policy.

The rapidly growing global demand for disaster risk information provides the scientific community with opportunities to consider how the dissemination of training modules and other capacity building tools can be achieved through existing and new technologies "that reach the last mile." These opportunities include methods for harmonizing internet, satellite communication, and other technologies, as well as making them accessible to remote locations. At the same time, despite a plethora of available training materials, standardized, peer-reviewed training resources are lacking, including training modules and tools that should be reviewed by the scientific community for their accuracy and reliability, in accordance with recognized quality assurance mechanisms.

Frequently, technologies are offered to developing countries that lack the capacity to absorb them and further develop and adapt them in their own context. Country capacity to assess technology and perform cost-effectiveness evaluations based on local parameters could be performed in higher-education institutions or dedicated organizations that set standards for best practice. These can be updated as new knowledge becomes available. The Best Available Technique and Best Environmental Practice (used by the European OSPAR Commission) ${ }^{47}$ are examples of conceptual tools that are multidisciplinary and aid in standardizing and improving practice in environmental protection.

The private sector is a key user of science, as well as a sponsor and creator of scientific discovery and invention. It is also a creator of risk, as well as a provider of critical services and products that can enhance the resilience of communities. Business associations, chambers of commerce, and other business fora should be seen as an opportunity to provide training on the role of the private sector in managing and reducing risk.

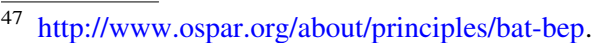

To date, the majority of the capacity development efforts have focused on highly specialized natural sciences (for example, geosciences). While there is an encouraging growth in social vulnerability research, disaster risk research capacity building should explicitly advance the multidisciplinary investigation of risks, and go beyond fragmented approaches to the understanding of risk (Holloway 2009; Cutter et al. 2015).

While there have been substantial and enabling investments in climate science, neither science funding bodies nor educational foundations have made resources available for "risk and resilience science," particularly in low- and middle-income countries where students cannot easily pursue DRR as a field of study or research. Evidence from PeriPeri U's 2015 summary evaluation report underlines that this represents one of the most substantial obstacles to advancing the field (Ofir and Mentz 2015). The Sendai Framework represents an opportunity to articulate the importance of resource investment in DRR as a growing field of research and practice globally.

\subsubsection{Research Gaps (Working Group 3)}

Despite efforts on the part of research and practice communities to create new understanding and be at the cutting edge of science, the vast scope and highly diverse nature of relevant research concepts, theories, methodologies, and empirical findings make it difficult to take stock of DRR knowledge. However, stock-taking is a critical step towards strengthening DRR as an area of scientific endeavor and translating emerging knowledge into more effective disaster plans, policies, and programs and to prevent duplication of effort.

Drawing on the reflections of other work streams, this working group aimed to identify research themes that require investment to strengthen the DRR research agenda and make progress on the implementation of the Sendai Framework (UNISDR 2016j). These themes are the multihazard approach and multidisciplinarity; the disaster cycle; knowledge sharing mechanisms; and knowledge coproduction.

Developing the Multi-Hazard Approach and Multidisciplinarity Hazardscapes are becoming increasingly broad and complex with the impact of climate change, but rapid economic development is also inextricably linked to disaster risk (IPCC 2012). As Superstorm Sandy illustrated in the United States, hurricane impacts can be expected to become more severe as a consequence of climate changeinduced sea level rise (Horton et al. 2015). Wildfires are becoming more dangerous and costly across the globe, in part because of our changing climate, but also because of 
settlement patterns that increase the exposure of people and property (IPCC 2012).

A comprehensive research agenda would start by clearly defining the problem (size, nature) before formulating solutions, how to implement them, and evaluating their effectiveness. A systematic assessment of existing knowledge should first focus on knowledge relevant to specific hazards and threats (UNISDR 2015a). This strategy would include taking stock of research on specific hazard types, such as atmospheric, seismic, environmental, biological, and technological hazards. We could begin by asking "What do we know?", "What do we not know?", and "What do we need to know?" about the nature of these threats, reflecting on the outputs to address the user needs and implementing groups such as funders of research and policy decision makers.

An assessment could be made of how disaster risk (in its multiple dimensions, including vulnerability and exposure) cuts across many relevant disciplines. This second step would examine the interdependencies between risk generation from different hazards (for example, fires subsequently followed by floods and landslides) and cascading events (for example, the 2011 earthquake-tsunami-nuclear disaster that affected Japan) (Kumasaki et al. 2016) that add complexity to the hazardscape (IPCC 2012; Gill and Malamud 2014).

There has been a strong movement over the past two decades towards multidisciplinary research involving collaboration between geophysical, social, and engineering scientists. It is important to ask how the integration of existing knowledge through multidisciplinary work has furthered our understanding or may do so in the future.

\section{Understanding Disaster Risk Management Holisti-} cally Focusing on all elements of disaster risk management (all four phases of the disaster cycle, that is, mitigation, preparedness, response, and recovery) allows us to consider how a wide range of activities associated with technology, development, governance, risk management, risk communication, and local capacity influence how we think about and approach disaster risk. This strategy will also distinguish between temporal phases that have been studied extensively and those on which less research has been undertaken.

Extensive research exists to guide risk reduction practices and policy making. However, new research paradigms are calling into question the very nature of mainstream thinking with respect to disaster risk. For example, in the health sciences, an expansion of the understanding of health risk has occurred to include the upstream factors behind health outcomes including socioeconomic inequalities and unfair power structures (CSDH 2008).

Similarly, in DRR, such paradigms view the roots of disaster as endogenous to the social order rather than external to it and ask us to consider how historic and current patterns of social organization, governance, and development create the contexts that contribute to the escalation of risks that eventually manifest as disasters (Mileti 1999; Wisner et al. 2004; Tierney 2014). This perspective would necessarily call for a reassessment of research and practice and may facilitate collaboration across disciplines (UNISDR 2015a, c).

Catalyzing Knowledge Sharing As discussed by Working Group 2, scientific training in the future should facilitate the development of scientific and technical skills that can integrate knowledge from different disciplines and produce holistic risk and impact information that addresses hazards, exposure, and vulnerability and capacity (UNISDR 2013). The global scale of this effort requires that we reconsider the factors that both facilitate and impede global science sharing and research applications, including language barriers, working cultures, and the wider societal context.

The extent to which knowledge and solutions developed in specific societal contexts can be generalized to others is unclear in DRR. Related questions exist regarding the scalability and transferability of DRR strategies. It is critical to begin to unpack these complexities and their implications for DRR.

Coproducing Knowledge New participatory approaches are needed in future DRR research. Tacit knowledge and risk and resilience experience of at-risk communities can co-produce knowledge related to hazards and disasters. Such collaborations could include (but are not limited to) the incorporation of indigenous perspectives and knowledge and using a variety of "citizen science" programs.

\subsection{Side Events}

The conference side events (Table 2) were organized as short sessions to complement the main scientific content of the conference and highlight important themes such as research ethics. The side events offered the opportunity for participants to provide input into the Road Map and strengthen its ownership across DRR communities, particularly young people. Funding for DRR research and how dissemination and access to research and knowledge could 
Table 2 Side events of the UNISDR S\&T Conference

\begin{tabular}{ll}
\hline Side events & Brief description \\
\hline $\begin{array}{l}\text { (1) Knowledge Hubs for DRR Science for the } \\
\text { Implementation of the Sendai Framework (UNISDR }\end{array}$ & $\begin{array}{c}\text { Focused on knowledge platforms for sharing S\&T information and expertise to } \\
\text { strengthen DRR policies and operations }\end{array}$ \\
$\begin{array}{l}\text { 2016k) } \\
\text { (2) Science and Technology for Addressing Gender }\end{array}$ & $\begin{array}{c}\text { Focused on how to improve women and girls' access to DRR knowledge and } \\
\text { their participation as scientists and knowledge makers in DRR decision } \\
\text { making }\end{array}$ \\
$\begin{array}{l}\text { (3) Supportive Publishing Practices in DRR: Leaving No } \\
\text { Scientist behind (UNISDR 2016m) }\end{array}$ & $\begin{array}{c}\text { Focused on discussing challenges in dissemination of knowledge through } \\
\text { publishing and how access to high quality DRR research especially in low- and } \\
\text { middle-income countries can be improved through better publishing practices }\end{array}$ \\
$\begin{array}{l}\text { (4) The Role of Youth in the Application of Science for DRR } \\
\text { (UNISDR 2016n) }\end{array}$ & $\begin{array}{c}\text { Focused on challenges to youth participation in DRR S\&T and possible solutions } \\
\text { including a youth DRR platform }\end{array}$ \\
(5) Bioethics and Ethics of Science and Technology in DRR & $\begin{array}{c}\text { Focused on challenges in maintaining ethical DRR S\&T practices and discussed } \\
\text { possible solutions }\end{array}$ \\
(UNISDR 2016o) & $\begin{array}{c}\text { Focused on how research funding can be effectively used and aligned with } \\
\text { research gaps and priorities }\end{array}$ \\
\hline
\end{tabular}

be improved through enhanced publishing practices were also addressed. The side events raised the possibility of setting up specific platforms for ongoing discussion throughout the implementation of the Sendai Framework.

\subsubsection{Knowledge Sharing for DRR Science for the Implementation of the Sendai Framework: The Role of Knowledge Hubs}

Among the many calls to the scientific community in the Sendai Framework is a notable call "to promote the use and expansion of thematic platforms of cooperation, such as global technology pools and global systems to share know-how, innovation and research and ensure access to technology and information on disaster risk reduction" (UNISDR 2015b, Paragraph 47c). The UNISDR STAG 2015 report emphasized the importance of disseminating and translating scientific findings into usable knowledge for policy and planning (Aitsi-Selmi et al. 2015). It pointed out that "cross-disciplinary exchange will identify interdependencies which can help to identify findings for application to complex problems" (Aitsi-Selmi et al. 2015, p. 10) and highlighted the need for capacity development and specific tools to enable all levels of decision making in society to use scientific knowledge.

The group discussed opportunities and barriers to leveraging scientific knowledge to support prevention, preparedness, and response measures and the role that knowledge hubs might play in closing the science-policypractice gap. This supported complementary discussions in Work Stream 1 (partnerships and platforms) and Work Stream 4 (leveraging science).

Many organizations have taken the initiative to address these challenges using the support that can be provided by knowledge hubs, such as those shown in Table 3.

\subsubsection{Science and Technology for Addressing Gender Inequality of Disaster Risk}

Research has shown that women are more at risk of being affected by disasters and their aftermath (Enarson and Morrow 1998; Fordham 2003; Hines 2007). The multiple levels of discrimination that women can face-in education, healthcare, employment, and control of property-are key underlying drivers that inevitably make women more vulnerable in and after crises (Cannon 2002). Women and girls often suffer more pronounced socioeconomic losses associated with disasters and are more likely to experience increased poverty rates, higher rates of sexual violence, and a lack of adequate housing in the aftermath of a disaster (Henrici et al. 2010).

UNESCO $(2007,2010)$ reported that only $30 \%$ of scientists or researchers globally are women, normally due to lack of adequate education, cultural issues, political hurdles, and poverty. This lack of representation at both research and higher decision making levels means that the views and needs of women often are not explored, sought out, or addressed in science and technology and broader policy making.

The Sendai Framework recognizes the importance of implementing comprehensive gender-inclusive DRR plans and provides guidance by promoting the inclusion of women and girls within mainstream DRR policy (UNISDR 2015c): "Women and their participation are critical to effectively managing disaster risk and designing, resourcing and implementing gender-sensitive disaster risk reduction policies, plans and programmes; and adequate capacity building measures need to be taken to empower women for preparedness as well as to build their capacity to secure alternate means of livelihood in post-disaster situations" (UNISDR 2015b, Paragraph 35a(i)). 
Table 3 Examples of existing knowledge hub initiatives

\begin{tabular}{|c|c|}
\hline Knowledge hub initiative & Brief description \\
\hline The PreventionWeb ${ }^{\mathrm{a}}$ platform of UNISDR & $\begin{array}{l}\text { A participatory online portal that aims to cover the global DRR } \\
\text { domain. PreventionWeb contains policy and DRR organization } \\
\text { information. The Understanding Risk section translates complex } \\
\text { concepts into plain language }\end{array}$ \\
\hline
\end{tabular}

The Natural Hazards Center ${ }^{\mathrm{b}}$ (NHC) at the University of Colorado at Boulder

The World Health Organization (WHO) Regional Office for the Americas-Pan American Health Organization Knowledge Center on Public Health and Disasters ${ }^{\mathrm{c}}$

The EC Knowledge Centre for Disaster Risk Management ${ }^{\mathrm{d}}$ (EC DRM-KC)

The UK Department for International Development Building Resilience and Adaptation to Climate Extremes and Disasters ${ }^{\mathrm{e}}$ (BRACED) program

Pacific Disaster $\mathrm{Net}^{\mathrm{f}}(\mathrm{PDN})$

Pacific Catastrophe Risk Assessment and Financing Initiative ${ }^{\mathrm{g}}$ (PCRAFI)

The University of South Pacific Knowledge Centre ${ }^{\mathrm{h}}$

Global Alliance of Disaster Research Institutes ${ }^{\mathrm{i}}$ (GADRI)

International Centre for Water Hazard and Risk Management $\mathrm{t}^{\mathrm{j}}$ (ICHARM) under the auspices of UNESCO

Evidence Aid $^{\mathrm{k}}$
Started in 1976, a center that has collected and disseminated social and policy information; conducted research; supported quick-response studies following disasters; and provided educational opportunities

Focuses on public health and disasters, providing an open-access manual of the most important topics on public health and disasters

Launched by the European Commission in September 2015 to promote the interface between science, policy, and early warning systems by promoting networks, and support access and use of research

An example of an integrated approach to research, learning, and practice on DRR and adaptation, this supports evidence gathering and learning as a center for developing and disseminating knowledge on sustainable resilience

A disaster risk management web portal for the Pacific. The PDN was developed as an initiative of the Pacific Disaster Risk Management Partnership Network

A joint initiative that aims to provide the Pacific island countries (PICs) with modeling and assessment tools. It also supports integrated financial solutions for natural disasters and climate change

An online resource center for climate variability and change data and reports, including both scientific documents and traditional knowledge from the communities

A forum for sharing knowledge and promoting collaboration on DRR and resilience to disasters. Eighty-eight organizations (67 universities and 21 others) from 26 states are member institutes

Serves as the Global Centre of Excellence for Water Hazard and Risk Management by observing and analyzing natural and social phenomena, building capacities, and creating knowledge networks

Assesses published systematic reviews of relevance to natural disasters, humanitarian crises, or major healthcare emergencies, with partners including the International Rescue Committee and the Cochrane Library

\footnotetext{
a http://www.preventionweb.net/

b http://www.colorado.edu/hazards/

c http://www.saludydesastres.info/

${ }^{\mathrm{d}}$ http://drmkc.jrc.ec.europa.eu/

e http://www.braced.org/

${ }^{\mathrm{f}} \mathrm{http}: / / \mathrm{www} \cdot$ pacificdisaster.net/

g http://pcrafi.sopac.org/

${ }^{\mathrm{h}}$ http://eugcca.usp.ac.fj/KnowledgeCentre.aspx

${ }^{\mathrm{i}}$ http://www.dpri.kyoto-u.ac.jp/gsri/s-description.html

${ }^{\mathrm{j}}$ http://www.icharm.pwri.go.jp/index.html

${ }^{\mathrm{k}} \mathrm{http} / / / \mathrm{www}$. evidenceaid.org/
}

Specific mention of women and science in the Sendai Framework provides a unique opportunity to build on the role of science in promoting the education and inclusion of women in DRR policy. This side event was an opportunity to agree on and champion initiatives to increase the contribution of women scientists as well as highlight gender- specific issues within the Science and Technology Road Map. Consensus was reached that research must be promoted to build on understanding the different needs faced by women during and after a disaster. Specific measures suggested included gender responsive early warnings; building (technical) capacities to enable better recovery 
and resilience; and supporting policies regarding collection, use, and analysis of sex and age disaggregated data.

The session participants recommended the establishment of a Women and Girls in DRR Science Platform, supported by the UNISDR, UNESCO, and UN Women. Existing networks championing gender-aware DRR practices will be utilized to facilitate this platform. Stakeholders that are already engaged in gender-focused work include the Gender Disaster Network ${ }^{48}$ (GDN), the UNESCO L'Oréal network, ${ }^{49}$ ICSU from within the DRR field, and initiatives such as the Athena SWAN Charter, ${ }^{50}$ which is committed to advancing women's careers in science, technology, engineering, maths, and medicine (STEMM) employment in higher education.

\subsubsection{Supportive Publishing Practices in DRR: Leaving No Scientist Behind}

The Sendai Framework goes beyond the Hyogo Framework in the emphasis it has placed on the role of science and its dissemination (Pearson and Pelling 2015). It promotes "the collection, analysis, management and use of relevant data and practical information and ensuring its dissemination, taking into account the needs of different categories of users, as appropriate" (UNISDR 2015b, Paragraph 24(a)). It also advocates moving away from silobased knowledge management and scientific systems and data towards "a multi-hazard approach and inclusive riskinformed decision-making based on the open exchange and dissemination of disaggregated data" (UNISDR 2015b, Paragraph 19(g)).

The side event participants recognized challenges for DRR publishing, including:

(1) Peer-review systems that are difficult to navigate;

(2) Accessing current research in order to shape research questions and data analysis strategies;

(3) Carrying out effective literature reviews across all 600 journals that regularly or occasionally cover DRR topics;

(4) Limiting monopolies of open-access publishing;

(5) Language and other publishing biases in the publications;

(6) Differences in research approaches and cultural practices; and

(7) Escalating publication costs in the face of diminishing research funds.

Achieving change requires the availability of suitable outlets for publishing research and information

\footnotetext{
$\overline{48}$ http://www.gdnonline.org/.

$49 \mathrm{https}: / / \mathrm{www}$.womeninscience.co.uk/.

${ }^{50}$ http://www.ecu.ac.uk/equality-charters/athena-swan/.
}

(UNISDR 2015b) and the participation of the full range of stakeholders, including developing countries and in languages other than English. Better opportunities can be created to ensure evidence is available for decision makers in humanitarian response situations, for example, through initiatives like Evidence Aid. Building the capacity of all authors including in low- and middle-income countries could be addressed by following for example the mentoring approach taken by AuthorAid ${ }^{51}$ on writing peer-reviewed papers. Access to and dissemination of research could be further improved through the financial support given to authors for example by Frontiers publications who offer to waive publication charges. Frontiers publications will also be launching the "Community Case Study" to encourage contributions from the wider, non-academic research community.

To improve DRR knowledge dissemination systems, joint efforts are being made to ensure that EU research contracts from 2020 on will include clauses to ensure publication standards and ethics are respected and that published research is reproducible. Further work on using partnerships, the role of knowledge hubs, and funding structures to ensure access to research that is of high quality while being inclusive, should be prioritized. This speaks to the discussions in other work streams and side events.

Relatively new models of publications such as electronic media and open-access platforms are proliferating and may overtake printing in the near future. These can help to address accessibility and inclusivity issues. However, these can also reinforce pre-existing differences in access caused by access to the internet. Cost-free, crowd-sourcing models that remove barriers to entry to scientific activities are beginning to develop (Lin 2011). The large number of journals and other sources to draw from creates a challenge for practitioners who require multi-hazard, multidimensional approaches to disaster risk.

The needs of different audiences and users of research (including local communities) must be taken into account for the effective dissemination of research. Users of research outputs such as decision makers are often concerned that the best research in terms of quality does not address the problems they face in their roles. This can be improved by a better dialogue between the different stakeholders. Similarly, translating research that is already available into practical messages is a critical step in improving DRR.

\subsubsection{The Role of Youth in the Application of Science for Disaster Risk Reduction}

The Sendai Framework stresses the importance of diverse perspectives in all DRR processes: "A gender, age,

$\overline{51}$ http://www.authoraid.info/. 
disability and cultural perspective should be integrated in all policies and practices, and women and youth leadership should be promoted" (UNISDR 2015b, Paragraph 19d). The Sendai Framework places importance on the role of young people as "agents of change" for DRR and heavily emphasizes the importance of science and technology as enablers for implementing and monitoring resilient programs (UNISDR 2015b, Paragraph 36a(ii)).

Engaging young scientists and promoting their continuous interaction with young persons engaged in policy design and implementation, alongside inter-generational dialogue, is vital. The UN Major Group for Children and Youth (UN MGCY) coordinates young people's participation in intergovernmental and allied processes.

Challenges remain in meaningfully engaging young scientists with the main barriers being a lack of funding and support, as well as poor job security among young people currently. The side event helped to develop recommendations for the S\&T Road Map and its work plan to increase intergenerational knowledge exchange, promotion and use of young scientists' work, skills, network development mechanisms, and access to funding.

In addition, the Young Scientists Platform on $\mathrm{DRR}^{52}$ was launched at the S\&T Conference, and provides an example of a collaborative platform that can facilitate the collective sharing of information to build capacity and provide a channel to support and engage young people with the support of STAG among others. This platform will provide young scientists with a means to contribute to the implementation of the Science and Technology Road Map, enriching the implementation and monitoring of the Sendai Framework. The partnership can facilitate mentoring and sharing research and professional opportunities for young DRR scientists.

\subsubsection{Bioethics and the Ethics of Science and Technology in DRR}

The Sendai Framework pursues a moral aim to substantially reduce the disaster losses of lives and assets from both natural and human-made disasters worldwide. Ethical reflections extend beyond issues of safety and public health, to address the impacts of policies and interventions on human dignity, justice, and social responsibility. Particular consideration is needed regarding the special vulnerability of affected populations, which may reduce their capacity to influence interventions once a disaster has struck (as illustrated by the Ebola virus epidemic in West Africa).

It is important to recognize that scientific and technological applications could lead to unintended negative consequences in parallel to their benefits. A comprehensive

$\overline{52}$ http://childrenyouth.org/category/disaster-risk-reduction/. approach to DRR must include policies for the ethical evaluation of scientific and technological applications that could have widespread and diverse impacts. An overarching issue is that ethical frameworks are tacit as well as diverse as multiple organizations and disciplines are engaged throughout the disaster cycle. This presents the need for a common set of ethical principles that are flexible and adaptable to various DRR contexts (UNISDR 2015b).

The need for transparency in decision making to address inequality and opportunism during disasters was raised by the side event participants. Data sharing, risk communication, and capacity building in a manner that respects confidentiality, autonomy, and dignity and is culturally sensitive require common ethical foundations. Numerous publications and reflections on bioethical issues in disaster response and prevention, including research conducted during disaster situations but also proposed principles for climate change mitigation and adaptation, are available. A number of examples are shown in Table 4.

To resolve these complex challenges, it was recommended that a DRR Ethics Platform should be established with a mandate to ensure that ethics is mainstreamed across DRR work. The platform's outputs will include proposing universal ethical guidelines, and publishing case studies on good and bad practices to promote the use of ethical principles in all aspects of DRR.

\subsubsection{Research Funding}

The Sendai Framework calls for the greater effectiveness of funding investments to support DRR innovation, identify research gaps, and prioritize research areas appropriately (UNISDR 2015b, Paragraph 25g). The scope and severity of increasing or persistent disaster risks and losses (IPCC 2012; World Bank 2013, 2015) indicate fundamental gaps in our knowledge of how disaster risk is created, distributed, prevented, and/or reduced, as well as the lack of effectively and systematically translating existing knowledge into practice. The need to optimize national and international cooperation in relation to resourcing research and facilitating its uptake is mentioned throughout the Sendai Framework.

It is critical to identify that there are often capacity, resource, and cultural differences between organizations and between countries. Variations in language, information access, expectations for scientific rigor, and work culture influence how research is resourced, conducted, and applied. Significant global differences with respect to wealth and economic well-being, political systems and governance (for example, accountability and the rule of law) influence DRR capacity and the extent to which research and resources can be aligned. Discussions of this side event focused on how DRR funding mechanisms are operating, why they are siloed 
Table 4 Examples of initiatives addressing ethical issues in DRR

\begin{tabular}{|c|c|}
\hline Bioethics and ethics initiative & Brief description \\
\hline $\begin{array}{l}\text { The UNESCO World Commission on the Ethics of Scientific } \\
\text { Knowledge and Technology }{ }^{\mathrm{a}} \text { (COMEST) }\end{array}$ & $\begin{array}{l}\text { A preliminary nonbinding declaration on ethical principles relating to } \\
\text { climate change that reflects on the moral basis of our responses to climate } \\
\text { change }\end{array}$ \\
\hline The United Nations International Law Commission ${ }^{\mathrm{b}}$ & $\begin{array}{l}\text { Working on the protection of persons in the event of disasters (art. 1) in } \\
\text { order to meet their essential needs with full respect of their rights (art. 2). } \\
\text { The Commission also expressly recognizes the duty to respect and protect } \\
\text { the inherent dignity of the person (art. 5) }\end{array}$ \\
\hline World Health Organization $(\mathrm{WHO})^{\mathrm{c}}$ & Building institutional capacity in countries to work on bioethics \\
\hline $\begin{array}{l}\text { United Nations Educational, Scientific and Cultural Organization } \\
{\text { (UNESCO })^{\mathrm{d}}}\end{array}$ & Building institutional capacity in countries to work on research ethics \\
\hline $\begin{array}{l}\text { EU-Funded European Cooperation in Science and Technology } \\
\text { (COST) Action }{ }^{\mathrm{e}} \text { on Disaster Bioethics }\end{array}$ & $\begin{array}{l}\text { Promoting multidisciplinary trans-national cooperation among researchers, } \\
\text { engineers, and scholars across Europe on bioethical issues in DRR }\end{array}$ \\
\hline $\begin{array}{l}\text { EC-Funded Stakeholders Acting Together On the ethical impact } \\
\text { assessment of Research and Innovation (SATORI) Project }{ }^{\mathrm{f}}\end{array}$ & $\begin{array}{l}\text { Currently working on providing a comprehensive overview of how ethics } \\
\text { assessment takes place }\end{array}$ \\
\hline EC-Funded RESPECT ${ }^{\mathrm{g}}$ Project & $\begin{array}{l}\text { Facilitating a global collaborative effort to improve adherence to high } \\
\text { ethical standards in research }\end{array}$ \\
\hline
\end{tabular}

${ }^{a}$ http://www.unesco.org/new/en/social-and-human-sciences/themes/comest/

b http://legal.un.org/ilc/guide/6_3.shtml

${ }^{\mathrm{c}}$ http://www.who.int/ethics/Ethics_basic_concepts_ENG.pdf

${ }^{\mathrm{d}}$ http://en.unesco.org/system/files/Building\%20Regional\%20Capacity\%20in\%20Bioethics\%20and\%20Ethics\%20of\%20Science\%20and\% 20Technology\%20(Regional\%20BEST\%20Capacity).pdf

e http://disasterbioethics.eu

${ }^{\mathrm{f}} \mathrm{http}: / /$ satoriproject.eu/

g http://www.respectproject.org/main/index.php

and conflicting in some cases, and how to coordinate them better to be mutually reinforcing.

Several platforms (for example, IRDR, FutureEarth, ${ }^{53}$ The Belmont Forum, ${ }^{54}$ and Newton Fund ${ }^{55}$ ) have been developed to stimulate trans-sectoral, national, or international research, bringing together research providers and research users from multiple sectors or countries. The participants in this side event built on discussions in Work Stream 1 to identify how these networks and platforms could be utilized to galvanize resources to support international research agendas and what barriers exist in current funding models. Discussions considered mechanisms for coordinating funders and the role of funders in supporting research capacity in countries with more limited research infrastructure.

\section{The Way Forward: Opportunities for DRR Science in 2015-2030; the S\&T Road Map and the S\&T Partnership}

The conference aimed to achieve the following outcomes (UNISDR 2015d):

\footnotetext{
$\overline{53}$ http://www.futureearth.org/.

$54 \mathrm{http}: / /$ www.belmontforum.org/.

55 http://www.newtonfund.ac.uk/.
}

(1) Critically appraising and endorsing the UNISDR Science and Technology Road Map to promote and support the availability and application of science and technology to decision making in DRR for implementation of the Sendai Framework;

(2) Ensure that the requirements and needs of users of science are met in the UNISDR Science and Technology Road Map;

(3) Discuss research and capacity development agendas for the UNISDR Science and Technology Road Map in support of the implementation of the Sendai Framework;

(4) Discuss and agree on the work methods for the UNISDR Science and Technology Partnership to support the Science and Technology Road Map for the implementation of the Sendai Framework. The Partnership will undertake key actions identified in the Science and Technology Road Map reflecting the six scientific functions: assessment, synthesis, science advice, monitoring and review, capacity development, and communication and engagement;

(5) Contribute concrete initiatives from the science and technology community and other stakeholders to support a comprehensive, multidisciplinary evidence-based approach to DRR policy options and interaction with decision makers at all levels; and 
(6) Strengthen national science advisory capacities leveraging existing science networks and policy platforms.

The conference successfully launched the Science and Technology Partnership, and crystalized an agenda for the science and policy community to support the implementation of the Sendai Framework. The latter is reflected in the S\&T Road Map (UNISDR 2016q). A number of concrete recommendations came out of the conference and include:

(1) Need for formal "national DRR science-policy councils/platforms" or a form of national focal points for science to support disaster risk reduction and management plans identified. Focal points could include platforms or chief scientific advisors function.

(2) Focusing more attention on understanding the root causes and underlying risk factors of disaster risk including interlinkages between DRR, sustainable development, and climate change mitigation and adaptation, and ensuring DRR is mainstreamed into other sectors, policies, and strategies. A call for an evidence-based review of risk assessment and its implementation was made.

(3) Conducting a periodic review of knowledge needs, new science (including implementation science), and research gaps. More effort is needed to work out how to achieve this and ensure avoiding duplication of effort.

(4) Using the expanding S\&T evidence base to support capacity building and ensure that capacity development for disaster risk management is interdisciplinary, shared across international boundaries, and demand-driven.

(5) Leveraging science for DRR through innovative schemes that are long-term and provide opportunities to enhance the dialogue between decision makers and researchers through interdisciplinary and participatory networks to ensure integrated disaster risk governance.

(6) Supporting integrated and holistic approaches to the use of S\&T for DRR that reflect the wide scope of the Sendai Framework, which applies to disasters caused by natural or human-made hazards, as well as environmental, technological, and biological hazards.

(7) Enhancing the role of social science in the multidisciplinary effort to understand behavior and decision making in DRR and the role of the wider societal context in disaster risk creation and reduction, and incorporating key markers of socioeconomic vulnerability.

(8) Supporting open access, multi-hazard data platforms and standardized approaches and tools to map and use of data and scenarios that make science sensible to decision makers and the general public.

(9) Using participatory approaches for communities to work together to co-produce risk knowledge, define options, and support evidence-based decision making. Users must be included in the earliest stages of developing research and technology, including through improved dialogues with citizen groups, involvement of local and national universities and institutions, young scientists, and the use of indigenous knowledge.

(10) Documenting and analyzing the effects of disasters and DRR interventions, including ethical implications of scientific research.

(11) Strengthening DRR science-policy and cross-sectoral dialogues to facilitate risk assessments, postdisaster reviews, data sharing, and decision making. (12) Producing guidelines for evidence-based risk assessments and their implementation to support the practical application of risk assessment.

Other notable outcomes included the proposal to launch a Women in DRR Science platform supported by UN Women, UNISDR, and UNESCO; and the launch of the Young Scientists in DRR platform that is coordinated by the UN Major Group for Children and Youth. The official conference outcomes are summarized on the conference website (UNISDR 2016r).

Acknowledgments The authors would like to express their gratitude to the UNISDR Science and Technology Conference Organizing Committee and their organizations; the Organizing Partners and wider partners who sponsored the event; everyone involved with preparing the materials and organizing the conference, including UNISDR and Public Health England (PHE); those who provided comments and feedback on the Science and Technology Road Map; and most importantly the participants in the conference, as well as those who submitted abstracts, including individuals who were unable to attend for funding or other reasons.

Open Access This article is distributed under the terms of the Creative Commons Attribution 4.0 International License (http://crea tivecommons.org/licenses/by/4.0/), which permits unrestricted use, distribution, and reproduction in any medium, provided you give appropriate credit to the original author(s) and the source, provide a link to the Creative Commons license, and indicate if changes were made.

\section{Acronyms}

3rd WCDRR Third World Conference on Disaster Risk Reduction

BRACED Building Resilience and Adaptation to Climate Extremes and Disasters Programme

CDKN Climate and Development Knowledge Network 
COMEST

CoP21

COST

CRED

DRM

DRR

EC

EC DRM-KC

EC JRC

EFAS

EFFIS

EM-DAT

EU

FAO

GADRI

GAR

GDACS

GDN

GEM

GEO

GEOSS

GFCS

GFDRR

GIEWS

GIS

GPS

HFA

HOT

IAP

ICHARM

$\mathrm{ICoE}$

ICSU

ICT

IDB

IEC

IGOs
UNESCO World Commission on the Ethics of Scientific Knowledge and Technology

2015 Paris Climate Conference

European Cooperation in Science and Technology

Centre for Research on the IPCC

Epidemiology of Disasters

Disaster Risk Management

Disaster Risk Reduction

European Commission

European Commission Disaster Risk

Management Knowledge Centre

European Commission Joint Research

Centre

European Flood Alert System

European Forest Fire Information

System

Emergency Events Database

European Union

Food and Agriculture Organization

Global Alliance of Disaster Research

Institutes

Global Assessment Report

Global Disaster Alerts and

Coordination System

Global Development Network

Global Earthquake Model

Group on Earth Observations

Global Earth Observation System of Systems

Global Framework for Climate Services

Global Facility for Disaster Reduction and Recovery

FAO Global Information and Early

Warning System

Geographic Information Systems

Geographical Position Systems

Hyogo Framework for Action 2005-2015

Humanitarian OpenStreetMap Team

ISDR-Asia Partnership

International Centre for Water Hazard

and Risk Management

International Centres of Excellence

International Council for Science

Information and Communication

Technology

Inter-American Development Bank

International Electrotechnica

Commission

Intergovernmental Organizations
IGU

IHR

IIASA

INASP

IPCC SREX

IRDR

ISDR

ISO

ISSC

JICA

LAC

LDCs

NGOs

NHC

NHP

NIED

NSF

NSOs

ODI

OECD

PCRAFI

PDN

PeriPeri U

PHE

PICs

RADAR

RMS

S\&T

SAARC

SATORI

SDGs

SEI

SIDS
International Geographical Union

International Health Regulations

International Institute for Applied Systems Analysis

International Network for the Availability of Scientific Publications

Intergovernmental Panel on Climate Change

Intergovernmental Panel on Climate Change Special Report on Managing the Risks of Extreme Events and Disasters to Advance Climate Change Adaptation

Integrated Research on Disaster Risk

International Strategy for Disaster

Reduction

International Organization for

Standardization

International Social Science Council

Japan International Cooperation

Agency

Latin America and Caribbean Region

Least Developed Countries

Nongovernmental Organizations

Natural Hazards Center

Natural Hazards Partnership

National Research Institute for Earth

Science and Disaster Prevention

National Science Foundation

National Statistical Offices

Overseas Development Institute

Organisation for Economic Cooperation and Development

Pacific Catastrophe Risk Assessment and Financing Initiative

Pacific Disaster Net

Partners Enhancing Resilience for People Exposed to Risks

Public Health England

Pacific Island Countries

Research Alliance for Disaster and Risk Reduction

Risk Management Solutions

Science and Technology

South Asia Association of Regional Cooperation

Stakeholders Acting Together On the ethical impact assessment of Research and Innovation

Sustainable Development Goals

Stockholm Environment Institute

Small Island Developing States 
STEMM Science, Technology, Engineering, Maths and Medicine

TRUST Transitions to the Urban Water Services of Tomorrow

$\mathrm{UCL}$

UCT

UK

UN

UKCDS

UNECE

UNESCAP

UNESCO

UNISDR

UNISDR STAG United Nations International Strategy for Disaster Reduction, Scientific and Technical Advisory Group

UN MGCY UN Major Group for Children and
Youth

UN-SPIDER UN Platform for Space-based Information for Disaster Management and Emergency Response

UNU United Nations University

UNU-EHS United Nations University-Institute for Environment and Human Security

UNU-IIGH United Nations UniversityInternational Institute for Global Health

WHO

WHS

WMO

WMO WIS

World Humanitarian Summit

World Meteorological Organization

World Meteorological Organization Information System

\section{References}

Aitsi-Selmi, A., K. Blanchard, D. Al-Khudhairy, W. Ammann, P. Basabe, D. Johnston, L. Ogallo, T. Onishi, O. Renn, A. Revi, C. Roth, P. Shi, J. Schneider, D. Wenger, and V. Murray. 2015. UNISDR Science and Technical Advisory Group report 2015: Science is used for disaster risk reduction. http://preventionweb. net/go/42848. Accessed 08 Feb 2016.

Alcántara-Ayala, I., O. Altan, D. Baker, S. Briceño, S. Cutter, H. Gupta, A. Holloway, A. Ismail-Zadeh, et al. 2015. Disaster risks research and assessment to promote risk reduction and management. Paris: ICSU. http://www.icsu.org/science-for-policy/disas ter-risk/documents/DRRsynthesisPaper_2015.pdf. Accessed 01 Mar 2016.

Burton, C.G., and V. Silva. 2014. Integrated risk modelling within the Global Earthquake Model (GEM): Test case application for Portugal. Proceedings of the Second European Conference on Earthquake Engineering and Seismology, 25-29 August 2014, Istanbul.

Calkins, J. 2015. Moving forward after Sendai: How countries want to use science, evidence and technology for disaster risk reduction. PLOS Currents Disasters. doi:10.1371/currents.dis. 22247d6293d4109d09794890bcda1878.

Cannon, T. 2002. Gender and climate hazards in Bangladesh. Gender and Development 10(2): 45-50.

Carabine, E. 2015. Revitalising evidence-based policy for the Sendai framework for disaster risk reduction 2015-2030: Lessons from existing international science partnerships. PLOS Currents Disasters. doi: 10.1371/currents.dis.aaab45b2b4106307ae2168a485e03 b8a.

Cardona, O.D., and M.L. Carreño. 2013. System of indicators of disaster risk and risk management for the Americas: Recent updating and application of the IDB-IDEA approach. In Measuring vulnerability to natural hazards: Toward disaster resilient societies, 2nd edn., ed. J. Birkmann, 251-276. Tokyo: United Nations University Press.

Carreño, M.-L., O.D. Cardona, and A.H. Barbat. 2007. Urban seismic risk evaluation: A holistic approach. Natural Hazards 40(1): 137-172.

CDKN (Climate and Development Knowledge Network). 2012. Promoting extreme event learning through serious fun. http:// cdkn.org/2012/05/promoting-extreme-event-learning-throughserious-fun/. Accessed 03 Mar 2016.

Corbane, C., T. De Groeve, D. Ehrlich, and K. Poljansek. 2015. A European framework for recording and sharing disaster damage and loss data. The International Archives of the Photogrammetry, Remote Sensing and Spatial Information Sciences XL-3/W3: 277-283.

Corfee-Morlot, J., I. Cochran, S. Hallegatte, and P.J. Teasdale. 2011. Multilevel risk governance and urban adaptation policy. Climatic Change 104(1): 169-197.

CSDH (The Commission on the Social Determinants of Health). 2008. Closing the gap in a generation: Health equity through action on the social determinants of health. Geneva: World Health Organization. http://apps.who.int/iris/bitstream/10665/ 43943/1/9789241563703_eng.pdf. Accessed 02 Mar 2016.

Cutter, S.L., and M. Gall. 2015. Sendai targets at risk. Nature Climate Change 5(8): 707-709.

Cutter, S.L., B.J. Boruff, and W.L. Shirley. 2003. Social vulnerability to environmental hazards. Social Science Quarterly 84(2): 242-261.

Cutter, S.L., A. Ismail-Zadeh, I. Alcántara-Ayala, O. Altan, D.N. Baker, S. Briceño, H. Gupta, A. Holloway, D. Johnston, G. McBean, Y. Ogawa, D. Paton, E. Porio, R.K. Silbereisen, K. Takeuchi, G.B. Valsecchi, C. Vogel, and G. Wu. 2015. Global risks: Pool knowledge to stem losses from disasters. Nature 522(7556): 277-279.

Daniell, J., A. Simpson, R. Murnane, A. Tijssen, A. Nunez, V. Deparday, R. Gunasekera, A. Baca, O. Ishizawa, and A. Schäfer. 2014. Review of open source and open access software packages available to quantify risk from natural hazards. Washington, DC: World Bank and Global Facility for Disaster Reduction and Recovery.

De Groeve, T., K. Poljansek, and D. Ehrlich. 2013. Recording disaster losses: Recommendations for a European approach. Ispra: European Commission Joint Research Centre.

Enarson, E., and B.H. Morrow. 1998. The gendered terrain of disaster: Through women's eyes. New York: Praeget.

Fordham, M. 2003. Gender, disaster and development: The necessity for integration. In Natural disasters and development in a globalizing world, ed. M. Pelling, 57-74. London: Routledge.

Foresight. 2012. Reducing risks of future disasters: Priorities for decision makers. London: The Government Office for Science. https://www.gov.uk/government/uploads/system/uploads/attach ment_data/file/286476/12-1289-reducing-risks-of-future-disas ters-report.pdf. Accessed 02 Mar 2016. 
Gaillard, J.C., and J. Mercer. 2012. From knowledge to action: Bridging gaps in disaster risk reduction. Progress in Human Geography 37(1): 93-114.

Gill, J.C., and B.D. Malamud. 2014. Reviewing and visualizing the interactions of natural hazards. Reviews of Geophysics 52(4): $680-722$.

Gill, J.C., and B.D. Malamud. 2016. Hazard interactions and interaction networks (cascades) within multi-hazard methodologies. Earth System Dynamics. doi:10.5194/esd-2015-94.

Group of Eight. 2013. The changing Ph.D. Discussion paper. Canberra: The Group of Eight House. https://go8.edu.au/publication/discus sion-paper-changing-phd. Accessed 10 Feb 2016.

Henrici, J.M., A.S. Helmith, and J. Bruan. 2010. Women, disasters, and Hurricane Katrina. Institute for Women's Policy Research Fact sheet. http://www.iwpr.org/publications/pubs/women-disas ters-and-hurricane-katrina. Accessed 02 Mar 2016.

Hines, R.I. 2007. Natural disasters and gender inequalities: The 2004 tsunami and the case of India. Race, Gender \& Class 4(1): $60-68$.

Holloway, A. 2009. Crafting disaster risk science: Environmental and geographical science sans frontières. International Journal of Community Research and Engagement 2: 98-118.

Horton, R., C. Little, V. Gornitz, D. Bader, and M. Oppenheimer. 2015. New York City Panel on Climate Change 2015 report chapter 2: Sea level rise and coastal storms. Annals of the New York Academy of Sciences 1336: 36-44.

HSI (Helvetas Swiss Intercooperation). 2011. Disaster risk reduction $\&$ development: Towards mainstreaming disaster risk reduction in development efforts. https://assets.helvetas.org/downloads/ 37_disasterriskreductionanddevelopmentdrr_global_red_final_ eng1_a4_portrait.pdf. Accessed 09 Feb 2016.

ICSU (International Council for Science). 2008. A science plan for integrated research on disaster risk: Addressing the challenge of natural and human-induced environmental hazards. http://www. icsu.org/publications/reports-and-reviews/IRDR-science-plan/ irdr-science-plan.pdf. Accessed 08 Feb 2016.

IPCC (Intergovernmental Panel on Climate Change). 2012. Managing the risks of extreme events and disasters to advance climate change adaptation. A special report of Working Groups I and II of the Intergovernmental Panel on Climate Change. Cambridge: Cambridge University Press.

IPCC (Intergovernmental Panel on Climate Change). 2014. Summary for policymakers. In Climate change 2014: Impacts, adaptation, and vulnerability. Part A: Global and sectoral aspects. Contribution of Working Group II to the fifth assessment report of the Intergovernmental Panel on Climate Change, ed. C.B. Field, V.R. Barros, D.J. Dokken, K.J. Mach, M.D. Mastrandrea, T.E. Bilir, M. Chatterjee, K.L. Ebi, Y.O. Estrada, R.C. Genova, B. Girma, E.S. Kissel, A.N. Levy, S. MacCracken, P.R. Mastrandrea, and L.L. White, 1-32. Cambridge: Cambridge University Press.

IRDR (Integrated Research on Disaster Risk). 2014. IRDR peril classification and hazard glossary. http://www.irdrinternational. org/2014/03/28/irdr-peril-classification-and-hazard-glossary/. Accessed $10 \mathrm{Feb} 2016$.

Ishigaki, K., and J. Mochizuki. 2014. Post-2015 framework for disaster risk reduction: A proposal for monitoring progress. Planet@Risk 2(5): 304-307.

Jensen, S.J., S. Feldmann-Jensen, D.M. Johnston, and N.A. Brown. 2015. The emergence of a globalized system for disaster risk management and challenges for appropriate governance. International Journal of Disaster Risk Science 6(1): 87-93.

Jones, L. 2012. The (not so) easy task of translating research into policy and practice. http://www.researchtoaction.org/2012/10/ the-not-so-easy-task-of-translating-research-into-policy-and-prac tice/. Accessed 10 Feb 2016.
Kawasaki, A., L.B. Berman, and W. Guan. 2013. The growing role of web-based geospatial technology in disaster response and support. Disasters 37(2): 201-221.

Kumasaki, M., M. King, M. Arai, and L. Yang. 2016. Anatomy of cascading natural disasters in Japan: Main modes and linkages. Natural Hazards 80(3): 1425-1441.

Lin, T. 2011. Cracking open the scientific process. New York Times, 16 January 2011. http://www.nytimes.com/2012/01/17/science/ open-science-challenges-journal-tradition-with-web-collaboration. html?_r=0. Accessed 10 Feb 2016.

Meyer, M. 2010. The rise of the knowledge broker. Science Communication 32(1): 118-127.

Mileti, D.S. 1999. Disasters by design. Washington, DC: Joseph Henry Press.

Murray, V. 2014. Disaster risk reduction, health, and the post-2015 United Nations landmark agreements. Disaster Medicine and Public Health Preparedness 8: 283-287.

ODI (Overseas Development Institute). 2013. Disaster risk management in post-2015 development goals: Potential targets and indicators. www.odi.org.uk/sites/odi.org.uk/files/odiassets/publi cations-opinion-files/8354.pdf. Accessed 02 Mar 2016.

OECD (Organisation for Economic Co-operation and Development). 2006. OECD studies in risk management: Japan earthquakes. http://www.oecd.org/japan/37377837.pdf. Accessed 08 Feb 2016.

OECD (Organisation for Economic Co-operation and Development). 2014. Improving the evidence base on the costs of disasters to inform better policy making for disaster risk management: Toward a framework for accounting national risk management expenditures and losses of disasters. http://www.oecd.org/gov/ risk/improving-the-evidence-base-on-the-costs-of-disasters.htm. Accessed 10 Feb 2016.

OECD (Organisation for Economic Co-operation and Development). 2015. Scientific advice for policy making: The role and responsibility of expert bodies and individual scientists. $O E C D$ Science, Technology and Industry Policy Papers. doi:10.1787/ 5js3311jcpwb-en.

Ofir, Z., and M. Mentz. 2015. Periperi U phase III summative evaluation. Report submitted to the research alliance for disaster and risk reduction. http://www.riskreductionafrica.org/wp-con tent/uploads/2016/02/PPU-Phase-III-Evaluation-Report-FINAL. pdf. Accessed 02 Mar 2016.

Pearce, L. 2003. Disaster management and community planning, and public participation: How to achieve sustainable hazard mitigation. Natural Hazards 28(2-3): 211-228.

Pearson, L., and M. Pelling. 2015. The UN Sendai framework for disaster risk reduction 2015-2030: Negotiation process and prospects for science and practice. Journal of Extreme Events 2(1):1571001. doi:10.1142/S2345737615710013.

Quarantelli, E.L. 1993. Converting disaster scholarship into effective disaster planning and managing: Possibilities and limitations. International Journal of Mass Emergencies and Disasters 11(1): $15-39$.

Rufat, S., E. Tate, C.G. Burton, and M.A. Sayeed. 2015. Social vulnerability to floods: Review of case studies and implications for measurement. International Journal of Disaster Risk Reduction 14: 470-486.

Schipper, L., and M. Pelling. 2006. Disaster risk, climate change and international development: Scope for, and challenges to, integration. Disasters 30(1): 19-38.

Shi, P., and R. Karsperson (eds.). 2015. World atlas of natural disaster risk. Heidelberg: Springer.

Shi, P., N. Li, Q. Ye, W. Dong, G. Han, and W. Fang. 2010. Research on integrated disaster risk governance in the context of global environmental change. International Journal of Disaster Risk Science 1(1): 17-23. 
Terry, J.P., and J. Goff (eds.). 2012. Natural hazards in the AsiaPacific region: Recent advances and emerging concepts. London: Geological Society.

Tierney, K. 2014. The social roots of risk: Producing disasters, promoting resilience. Palo Alto, CA: Stanford University Press.

Trainor, J.E., and T. Subbio (eds.). 2014. Issues in disaster science and management: A critical dialogue between researchers and practitioners. Emmitsburg, MD: Federal Emergency Management Agency Higher Education Program.

UNDP (United Nations Development Programme). 2004. Reducing disaster risk: A challenge for development. http://www.undp.org/ content/dam/undp/library/crisis\%20prevention/disaster/asia_paci fic/Reducing\%20Disaster\%20risk\%20a\%20Challenge\%20for\% 20development.pdf. Accessed 11 Feb 2016.

UNESCO (United Nations Educational, Scientific and Cultural Organization). 2007. Science, technology and gender: An international report. http://unesdoc.unesco.org/images/0015/ 001540/154045e.pdf. Accessed 02 Mar 2016.

UNESCO (United Nations Educational, Scientific and Cultural Organization). 2010. Women's and girls' access to and participation in science and technology. http://www.uis.unesco.org/ ScienceTechnology/Documents/unesco-egm-science-tech-gen der-2010-en.pdf. Accessed 02 Mar 2016.

UNESCO (United Nations Educational, Scientific and Cultural Organization). 2015. UNESCO intergovernmental oceanographic commission tsunami programme. http://www.ioc-tsu nami.org/. Accessed 06 Nov 2015.

UNISDR (United Nations International Strategy for Disaster Reduction). 2006. Global survey of early warning systems: An assessment of capacities, gaps and opportunities towards building a comprehensive global early warning system for all natural hazards. http://www.unisdr.org/2006/ppew/info-resources/ewc3/ Global-Survey-of-Early-Warning-Systems.pdf. Accessed $11 \mathrm{Feb}$ 2016.

UNISDR (United Nations International Strategy for Disaster Reduction). 2009. Terminology on disaster risk reduction. http://www. unisdr.org/we/inform/publications/7817. Accessed 19 Jun 2015.

UNISDR (United Nations International Strategy for Disaster Reduction). 2011. Hyogo framework for action 2005-2015: Building the resilience of nations and communities to disasters. Mid-term review 2010-2011. http://www.unisdr.org/we/inform/publica tions/18197. Accessed 08 Feb 2016.

UNISDR (United Nations International Strategy for Disaster Reduction). 2013. Global assessment report on disaster risk reduction 2013. http://www.preventionweb.net/english/hyogo/gar/2013/en/ home/index.html. Accessed 10 Feb 2016.

UNISDR (United Nations International Strategy for Disaster Reduction). 2014. Suggested elements for the post-2015 framework for disaster risk reduction (June 2014). https://www.unisdr.org/we/ inform/publications/37865. Accessed 09 Feb 2016.

UNISDR (United Nations International Strategy for Disaster Reduction). 2015a. Global assessment report on disaster risk reduction 2015. http://www.preventionweb.net/english/hyogo/gar/2015/en/ home/. Accessed 10 Feb 2016.

UNISDR (United Nations International Strategy for Disaster Reduction). 2015b. Sendai framework for disaster risk reduction 20152030. http://www.unisdr.org/files/43291_sendaiframeworkfordr ren.pdf. Accessed 10 Feb 2016.

UNISDR (United Nations International Strategy for Disaster Reduction). 2015c. Proposed updated terminology on disaster risk reduction: A technical review (August 2015). http://www. preventionweb.net/files/45462_backgoundpaperonterminologyau gust20.pdf. Accessed 09 Feb 2016.

UNISDR (United Nations International Strategy for Disaster Reduction). 2015d. Launching UNISDR science and technology partnership and the science and technology road map to 2030 .
Concept note. http://www.preventionweb.net/files/45270_con ceptnoteunisdrstconference2729ja.pdf. Accessed 10 Feb 2016.

UNISDR (United Nations International Strategy for Disaster Reduction). 2015e. Terms of reference of the scientific and technical partnership for the implementation of the Sendai framework for disaster risk reduction 2015-2030. http://www.preventionweb. net/files/45270_torofunisdrstpartnership.pdf. Accessed 04 Mar 2016.

UNISDR (United Nations International Strategy for Disaster Reduction). 2016a. Launching UNISDR science and technology partnership and the science and technology road map to 2030 . Short concept note: Work stream 1, working group 1. http:// www.preventionweb.net/files/45270_unisdrconceptnoteofws1. pdf. Accessed $11 \mathrm{Feb} 2016$.

UNISDR (United Nations International Strategy for Disaster Reduction). 2016b. Launching UNISDR science and technology partnership and the science and technology road map to 2030 . Short concept note: Work stream 2, working group 1. http:// www.preventionweb.net/files/45270_unisdrenws2wg1earlywar ningandhazard.pdf. Accessed 11 Feb 2016.

UNISDR (United Nations International Strategy for Disaster Reduction). 2016c. Launching UNISDR science and technology partnership and the science and technology road map to 2030 . Short concept note: Work stream 2, working Group 2. http:// www.preventionweb.net/files/45270_unisdrcnws2wg2vulnerabil ityandexpos.pdf. Accessed 11 Feb 2016.

UNISDR (United Nations International Strategy for Disaster Reduction). 2016d. Launching UNISDR science and technology partnership and the science and technology road map to 2030 . Short concept note: Work stream 2, working group 3. http:// www.preventionweb.net/files/45270_unisdrcnws 2 wg3riskassess mentandmang.pdf. Accessed $11 \mathrm{Feb} 2016$.

UNISDR (United Nations International Strategy for Disaster Reduction). 2016e. Launching UNISDR science and technology partnership and the science and technology road map to 2030 . Short concept note: Work stream 3, working group 1. http:// www.preventionweb.net/files/45270_unisdrcnws3wg1standard sandprotocols.pdf. Accessed 11 Feb 2016.

UNISDR (United Nations International Strategy for Disaster Reduction). 2016f. Launching UNISDR science and technology partnership and the science and technology road map to 2030 . Short concept note: Work stream 3, working group 2. http:// www.preventionweb.net/files/45270_unisdrcnws3wg2syenthese sandsharingd.pdf. Accessed 11 Feb 2016.

UNISDR (United Nations International Strategy for Disaster Reduction). 2016g. Launching UNISDR science and technology partnership and the science and technology road map to 2030 . Short concept note: Work stream 3, working group 3. http:// www.preventionweb.net/files/45270_unisdrcnws3wg3sharingin novations.pdf. Accessed 11 Feb 2016.

UNISDR (United Nations International Strategy for Disaster Reduction). 2016h. Launching UNISDR science and technology partnership and the science and technology road map to 2030 . Short concept note: Work stream 4, working group 1. http:// www.preventionweb.net/files/45270_unisdrcnws4wg1leveraging science.pdf. Accessed 11 Feb 2016.

UNISDR (United Nations International Strategy for Disaster Reduction). 2016i. Launching UNISDR science and technology partnership and the science and technology road map to 2030 . Short concept note: Work stream 4, working group 2. http:// www.preventionweb.net/files/45270_unisdrcnws4wg2capacityde velopment.pdf. Accessed $11 \mathrm{Feb} 2016$.

UNISDR (United Nations International Strategy for Disaster Reduction). 2016j. Launching UNISDR science and technology partnership and the science and technology road map to 2030 . Short concept note: Work stream 4, working group 3. http:// 
www.preventionweb.net/files/45270_unisdrcnws4wg3research gaps.pdf. Accessed 11 Feb 2016.

UNISDR (United Nations International Strategy for Disaster Reduction). 2016k. Launching UNISDR science and technology partnership and the science and technology road map to 2030. Short concept note: Side event. Knowledge sharing for DRR science for the implementation of the Sendai framework: The role of knowledge hubs. http://www.preventionweb.net/files/ 45270_unisdrcnknowledgehubssideevent.pdf. Accessed 11 Feb 2016.

UNISDR (United Nations International Strategy for Disaster Reduction). 2016 1. Launching UNISDR science and technology partnership and the science and technology road map to 2030. Short concept note: Side event. Science and technology for addressing gender inequality of disaster risk. http://www. preventionweb.net/files/45270_unisdrwomeninstfordrrconcept note.pdf. Accessed 11 Feb 2016.

UNISDR (United Nations International Strategy for Disaster Reduction). 2016m. Launching UNISDR science and technology partnership and the science and technology road map to 2030. Short concept note: Side event. Supportive publishing practices in DRR: Leaving no scientist behind. http://www.preventionweb. net/files/45270_unisdrcnpublishingpracticesindrr.pdf. Accessed $11 \mathrm{Feb} 2016$

UNISDR (United Nations International Strategy for Disaster Reduction). 2016n. Launching UNISDR science and technology partnership and the science and technology road map to 2030. Short concept note: Side event. The role of youth in the application of science for disaster risk reduction. http://www. preventionweb.net/files/45270_unisdrconceptnotetheroleo fyouthindr.pdf. Accessed $11 \mathrm{Feb} 2016$.

UNISDR (United Nations International Strategy for Disaster Reduction). 2016o. Launching UNISDR science and technology partnership and the science and technology road map to 2030 . Short concept note: Side event. Bioethics and ethics of science and technology in DRR. http://www.preventionweb.net/files/ 45270_unisdrcnethicssideevent.pdf. Accessed 11 Feb 2016.

UNISDR (United Nations International Strategy for Disaster Reduction). 2016p. Launching UNISDR science and technology partnership and the science and technology road map to 2030. Short concept note: Side event. Research funding. http://www. preventionweb.net/files/45270_unisdrcnresearchfunderssidee vent.pdf. Accessed 11 Feb 2016.

UNISDR (United Nations International Strategy for Disaster Reduction). 2016q. The science and technology roadmap to support the implementation of the Sendai framework for disaster risk reduction 2015-2030. http://www.preventionweb.net/files/ 45270_unisdrscienceandtechnologyroadmap.pdf. Accessed 04 Mar 2016.

UNISDR (United Nations International Strategy for Disaster Reduction). 2016r. Key messages. http://www.preventionweb.net/files/ 45270_unisdrscienceandtechnologyconferenc[2].pdf. Accessed 04 Mar 2016.

van Kerkhoff, L.E., and L. Lebel. 2015. Coproductive capacities: Rethinking science-governance relations in a diverse world. Ecology and Society 20(1). doi:10.5751/ES-07188-200114.

Weichselgartner, J., and R. Kasperson. 2010. Barriers in the sciencepolicy-practice interface: Toward a knowledge-action-system in global environmental change research. Global Environmental Change 20(2): 266-277.

White, G.F., R.W. Kates, and I. Burton. 2001. Knowing better and losing even more: The use of knowledge in hazard management. Global Environmental Change Part B: Environmental Hazards 3(3-4): 81-92.

WHO (World Health Organization). 2008a. Report of the WHO commission on the social determinants of health. http://www.who. int/social_determinants/thecommission/finalreport/en/. Accessed 02 Mar 2016.

WHO (World Health Organization). 2008b. International Health Regulations (2005), 2nd edn. Switzerland: World Health Organization.

WHO (World Health Organization). 2013. Statement to the 4th session of the global platform for disaster risk reduction 2013. http://www.preventionweb.net/globalplatform/2013/programme/ statements. Accessed 19 Jun 2015.

Wisner, B., P. Blaikie, T. Cannon, and I. Davis. 2004. At risk: Natural hazards, people's vulnerability and disasters. London: Routledge.

Witze, A. 2014. Tsunami alerts fail to bridge the "last mile". Nature News, 10 December 2014. http://www.nature.com/news/tsu nami-alerts-fail-to-bridge-the-last-mile-1.16516. Accessed 09 Feb 2016

World Bank. 2013. Building resilience: Integrating climate and disaster risk into development. Washington, DC: Global Facility for Disaster Risk Reduction, World Bank.

World Bank. 2015. The Sendai report: Managing disaster risks for a resilient future. Washington, DC: Global Facility for Disaster Risk Reduction, World Bank.

Zhou, H.J., X. Wang, and Y. Yuan. 2015. Risk assessment of disaster chain: Experience from Wenchuan earthquake-induced landslides in China. Journal of mountain science 12(5): 1169-1180. 